\title{
Profit Maximization and the Market Selection Hypothesis
}

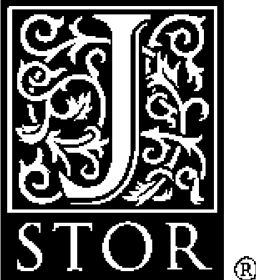

Prajit K. Dutta; Roy Radner

The Review of Economic Studies, Vol. 66, No. 4. (Oct., 1999), pp. 769-798.

Stable URL:

http:/links.jstor.org/sici?sici=0034-6527\%28199910\%2966\%3A4\%3C769\%3APMATMS\%3E2.0.CO\%3B2-1

The Review of Economic Studies is currently published by The Review of Economic Studies Ltd..

Your use of the JSTOR archive indicates your acceptance of JSTOR's Terms and Conditions of Use, available at http:/www.jstor.org/about/terms.html. ISTOR's Terms and Conditions of Use provides, in part, that unless you have obtained prior permission, you may not download an entire issue of a journal or multiple copies of articles, and you may use content in the ISTOR archive only for your personal, non-commercial use.

Please contact the publisher regarding any further use of this work. Publisher contact information may be obtained at http:/www.jstor.org/journals/resl.htmI.

Each copy of any part of a JSTOR transmission must contain the same copyright notice that appears on the screen or printed page of such transmission.

ISTOR is an independent not-for-profit organization dedicated to creating and preserving a digital archive of scholarly journals. For more information regarding ISTOR, please contact support@jstor.org. 


\title{
Profit Maximization and the Market Selection Hypothesis
}

\author{
PRAJIT K. DUTTA \\ Columbia University \\ and \\ ROY RADNER \\ New York University
}

First version received Aprit 1997; final version accepted December 1998 (Eds.)

\begin{abstract}
We examine the proposition that competitive find must behave as if they were maximizing profits; otherwise they would go bankrupt, or even fail to be financed in a competitive capital market. We investigate a model in which an entrepreneut raises funds for a risky enterprise on a competitive capital matket, by offering a "dividend policy" based on the realized (stochastic) flow of earnings. We show that an entrepreneur who maximizes the expected sum of discounted dividends is sure to fail in finite time. On the other hand, many other behaviouts yield positjve expected profits and ate able to attract investment funds, and yet result in a positive probability of surviving forever. As a consequence, if new firms have sufficiently diverse behaviours, then even if thete is a constant stream of new entrants, after a long time practically all of the survining firms will not have been marimizing profits.
\end{abstract}

\section{INTRODUCTION}

The dominant hypothesis in economics about the behaviour of firms is that of profit maximization: the managers of a firm make those choices that maximize the sum of current and future profits. The leading defence of this behavioural assumption is the market selection argument - in a "competitive environment", a firm whose managers do not maximize profits will eventually be driven out of the market. The argument is associated most directly with Milton Friedman (1953, essay 1); another prominent contributor to the early debate was Armen Alchian (1950). This paper investigates the question: (when) is the market selection argument a valid defence of the profit maximization hypothesis?

The market selection argument is premised on a simple point: for a firm to be successful, first, it has to attract investment funds and, second, it has to generate positive profits. So Alchian argues-" "this is the criterion by which the economic system selects survivors: those who realize positive profits are the survivors; those who suffer losses disappear ..." (p. 213). ${ }^{1}$ The content of the selection argument is that firms that maximize expected profits are (more likely to be) the survivors; they are better able to attract financing and have a higher probability of avoiding failure. Thus, ". . under a wide range of circumstances individual firms behave os if they were seeking rationally to maximize their expected.

1. Similarly, Friedman (1953, p. 22) says: "Whenever the determinant happens to lead to behavior consistent with rational and informed naximization of returns, the business will prosper and acquire resources with which to expand; whenever it does not, the business witl tend to lose resources and can be kept in existence only by the addition of resources from outside." 
returns . ." (Friedman, (1953, p. 21)). Friedman concludes: "the process of natural selection thus helps to validate the (profit maximization) hypothesis-or rather, given natural selection, acceptance of the hypothesis can be based largely on the judgement that it summarizes approximately the conditions for survival" (p. 22) ${ }^{2,3}$

Despite its popularity, there has been little rigorous analysis of the market selection argument. ${ }^{4}$ The early discussions were mainly set in deterministic models, (although even in this case it is problematic unless one adds a further assumption like constant returns to scale, or a potentially infinite supply of firtss of every type). ${ }^{5}$ The analysis is of greater interest, not to mention more realistic, in a world of uncertainty and dynamics; and this is the setting used in this paper.

Two methodological points about our analysis bear highlighting: first, we interpret profits, to investors in a firm, to be the expected sum of discounted ${ }^{6}$ distributions made to them out of cumulated earnings. Not all earnings are necessarily paid out to the investors, because retained earnings may be reinvested, used for working capital, or used as insurance against a future shortfall of working captal. Second, we maintain as a fact that a firm can fail if it is either unable to attract financing or if it runs out of working capital, i.e. if it goes bankrupt. ${ }^{7}$ We do not provide an explicit rationale for bankruptcy in this paper although we informally argue that it can be interpreted to be a consequence of costly refinancing (for a detailed discussion of this issue, see Section 6). Furthemore, as the discussions by Alchian and Friedman make clear, it is essential for the market selection argument that firms that consistently lose money be driven out of the market, i.e. bankruptcy is a minimal requirement of any model that examines the selection argument. ${ }^{8}$

We derive two main results. First, a profit-maximizing firm (i.e. a firm run by an entrepreneur/manager who maximizes profits) will, almost surely, fail in finite time. There are, however, a variety of non-profit-maximizing behaviours that have a positive probability of never failing. Our second result shows that if there is sufficient diversity in the set of potential fums, then some of the firms with a positive probability of survival will find financing in the capital market; consequently, after a long time, most of the surviving firms will not, in fact, be profit maximizers. Our conclusion, then, is the exact opposite of the market selection argument: firms that maximize profits are the least likely to be the

2. Alchian, to be fair, was more skeptical. He argued that success or survival onIy required relative superiority, and concluded that "the precise role and nature of putposive behaviot in the presence of uncertainty and incomplete information has not been completely understood" (Alchian (1950, p. 221)).

3. That the market disciplines is also asserted in discussions about individual behaviour; for example, Patei er $a$. (1991), in discussing financial markets, assert that "for most economists it is an article of faith that financial markets reach rational aggregate outcomes, despite the irrational behavior of some participants, since sophisticated players stand ready to capitalize on the mistakes of the naive" (p. 232).

4. The argument has not been without its critics. For thoughtful and critical discussions, as well as further references, see Winter (1987) and Nelson and. Winter (1982). These evolutionary analyses are further discussed in Section 6 .

5. Although the case of certainty is not our main focus, we do diseuss it briefly in the final section.

6. Expected profit appears to be the appropriate index under uncertainty and is the interpretation most widely employed. Friedman (p. 21, fn. 6) says, for example- "Given uncertainty, individuals or fitms choose among anticipated probability distributions of receipts or incomes. One hypothesis supposes them to be ranked ... by the mathematical expectation of money receipts. This is perhaps more applicable, and more frequently applied, to firms than to individuals." Of course, since our model is dynamic, we further take the discounted sum of these expected profits.

7. There is a third way in which an entrepreneur can "fail:" his fin may get taken over by other firns or his own shareholders). Allowing for take-overs may or may not alter our tesults significantly (see the discussion on this issue in Section 6).

8. A firm can of course lose money for a variety of reasons-mismanagement, an inferior product, as well as the pursuit of the "wrong" entrepreneurial goals. Alctian and Friedman would allow for the possibility, as do we, that such firms should also go bankrupt. 
market survivors. These results hold also in the case that new cohorts of firms arrive periodically in the market.

In order to explain the intuition of our results we need to give a brief description of the podel. We shall do this in a sequence that is the reverse of the actual timing structure; we shall first describe the working of a firm that is financed, and then turn to the working of the capital market. Also, the heuristic description will be of a discrete-time version of our continuous-time model.

Each firm produces a sequence of net earnings (or operating incomes), which are random variables with a Gaussian distribution. The stochastic process of eamings is controlled by an entrepreneur/owner who chooses every period, on the basis of the earnings history, a mean-variance pair out of a feasible set. (This set will, in general, depend on the firm's capital stock at time $t, Y(t)$; see below.) The net earnings in any period are added to the capital stock of the firm. Also, in each period the entrepreneur may withdraw part or all of the assets and distribute this to the investors and/or himself. However, the withdrawal must be nonnegative, and may not exceed the current capital stock. The evolution of the capital stock follows the obvious acounting equation: the capital stock at the beginning of the next period equals the current beginning-of-period stock, less the withdrawal, plus the current period's earnings. (The initial capital stock is given.) The firm is said to fail the first time that the capital stock reaches or falls below some specified level (e.g. zero)..$^{9}$

The technology of the firm is represented by a set of feasible mean-variance pairs for current earnings, which depends on the current capital stock. Technically, this mapping from the capital stock to the set of feasible current-earnings mean-variance pairs is called the technology correspondence, and it is assumed to exhibit decreasing retums to scale. The reason for this is quite simple; if there are constant or increasing returns to scale, then the maximum proft of the firm will be either infnite or zero. As a special case of decreasing returns we include bounded or constant size.

The intuition for our first result follows from the observation that every addition to the capital stock is costly for a profit-maximizing entrepreneur, since it represents foregone withdrawals. Since there are decreasing returns to the capital stock, eventually the marginal return to additions to the capital stock falls below the marginal utility to a dollar, i.e. one. At this point, it is better to pay out further earnings than to reinvest them. The optimal withdrawal policy for a profit-maximizing entrepreneur reaches the following balance: no withdrawals are made if the capital stock is below a critical level, denoted $b^{*}(>0)$, but if it exceeds this level, distributions are made as rapidly as possible ${ }^{10}$ in order to reduce the capital stock to $b^{*}$. The optimal critical level is finite because further growth is too costly in terms of foregone withdrawals. Consequently, the capital stock never grows bigger than $b^{*}$, but every time it reaches this critical level there is a positive probability that a run of losses will drive the firm towards bankruptcy. In the long run, it almost certainly will see some such string of losses.

There are, however, many other behaviours that, while not maximizing profits, do survive forever with positive probability. A simple example is a withdrawal policy that pays at a constant rate that is smaller than a feasible constant mean-earnings rate. There is a positive probability that for such a firm the capital stock will never drop to zero.

We also provide a complete characterization of the profit-maximizing mean-variance policy. It involves the entrepreneur taking on greater risk-i.e. increasing the variance (as

9. We admit the possibility that part of the initial capital stock might be illiquid.

10. We examine both the case in which there is some upper bound on the tate of withdrawal-recall the actual model is in continuous time-as well as the one in which unbounded withdrawals are possible. 
well as the mean of earnings) -as the capital stock increases. In fact, near zero capital stock, the entrepreneur acts as if he were only interested in firm survival whereas near $b^{*}$ he picks the maximum mean even if it comes with a high variance.

In the second step of our analysis we embed the firms in a capital market. We suppose that at time zero there is a population of potential start-up firms who will be demanders of investment funds, and a population of investors who will supply the capital to the firms. On the supply side we assume that investors are risk-neutral and have stationary preferences; this assumption that investors have the same preferences as profit-maximizing entrepreneurs would seem to be favourable to the market selection argument. On the demand side, each firm is characterized by its potential for earning (the technology correspondence) and the behaviour of its entrepreneur. Define the potential rate of return for a firm as the maximum return per dollar that this firm can generate for its investors; so it is the maximum, over initial capital stocks $y$, of $V(y) /(y+k)$, where $V(y)$ is the expected present value of the withdrawals generated by a profit-maximizing entrepreneur and $k$ is the size of start-up sunk capital. ${ }^{11}$ A firm will demand a positive amount of capital if the market rate of return is no more than its potential rate. The market rate is determined through usual supply-demand considerations in the (competitive) capital market.

If the market rate is exactly the same as the highest potential rate of return, then only profit maximizing entrepreneurs are ever funded (and all profits accrue to investors). However if the market rate is strictly less than the maximum potential-for example because the potential tate is sufficiently dispersed and the total demand is bounded-ther. part of the surplus generated by a firm accrues to its entrepreneur. ${ }^{12}$ Equivalently, an. entrepreneur can generate a return smaller than the maximum potential and yet attract financing. In this way, a non-profit-maximizing entrepreneur can be financed. Our second result then follows by showing that whenever the market rate is less than the maximum potential there are non-profit-maximizing behaviours which (a) can meet this rate and (b) can survive forever with positive probability.

The preceding discussion has dealt with the case of a single cohort of potential firms and investors who arrive at period 0 . We then extend the analysis to the case in which identical cohorts arrive in each successive time period, and show that a similar conclusion holds.

As noted above, our analysis is actually carried out in a model of continuous time. Accordingly, the cumulative earnings process is assumed to be a (controlled) diffusion, which one now routinely encounters in dynamic financial theory (see, e.g. Merton, 1990). Section 2 sets up the model of the firm, while Section 3 investigates the implication of profit-maximizing behaviour. In Section 4 the capital market is modelled and Section 5 generalizes the model to allow for entry. Section 6 contains concluding remarks; this is also the section where we discuss interpretations of the model and the possibility of further extensions of the basic framework. The proofs are gathered in the Appendix.

\section{THE MODEL}

The set-up of the model is as follows: an entrepreneur, with access to a project with known technology, makes an initial offering to the capital market. If he is successful at raising

I1. Note that because investors are tisk-neutral profit maximizers themselves, the potential rate of return of a firm is achieved when it is run as if the entrepreneur too were a profit-maximizer. Note also that the startup capital cost $k$ can be any non-negative amount.

12. Another sufficient condition for the market rate to be less than the maximum potential is that all. capital is liquid (see Section 4 for details). 
capital in the market, be proceeds to set up the firm, with this initial capitalization, and runs it until such time (if any) that the firm goes bankrupt. It will be convenient to present the model-and the subsequent analysis - in reverse order to the actual time-sequence. Accordingly we shall first discuss the working of a capitalized firm and then that of the capităl market.

\subsection{The firm: Technology, profits and bankruptcy}

Imagine that the entrepreneur has already obtained financing for the firm, and is ready to operate it. This financing includes the sunk investment, $k$, plus the initial liquid capital stock, $y>0$. The investment $k$ is not recoverable by the entrepreneur. It is a proxy, therefore, for such irreversible investments as payments made to financial institutions that manage the initial offering, legal fees, contracted commitments to productive resources, etc. ${ }^{13}$ The initial (liquid) capital, $y$, is determined as a residual; it is the amount of the capital that remains after subtracting $k$ from the total amount raised in the capital market.

We model time as a continuous variable, $t$, starting at $t=0$. The operation of the firm generates a flow of earnings; denote the net earning at instant $t$ by $d X(t)$. At instant $t$, the entrepreneur pays out to himself or his investors - i.e. withdraws - an amount $d W(t)$. Hence, the change in the capital stock of the firm at that instant is $d X(t)-d W(t)$. For mathematical reasons explained below, we keep track not of the instantaneous changes but rather of the accumulated changes, $X(t)$ and $W(t)$. The capital stock at time $t$ is defined by the equation

$$
Y(t)=y+X(t)-W(t)
$$

The firm fails - or goes bankrupt - at the first time $T$ (if any) at which the capital stock reaches or falls below 0 . If the firm never fails, we set $T$ equal to infinity, and say that the firm survives.

The entrepreneur controls the withdrawal process, subject to the constraint that it be nondecreasing and right-continuous. (This corresponds to the condition that the "withdrawal rate" $d W(t)$ be nonnegative but may be unbounded.) The entrepreneur may also influence the (accumulated) earnings process, as follows. The earnings process is assumed to be a diffusion, with time-varying drift and volatility. We shall give a precise definition shortly, but the heuristic description of the evolution of $X(t)$ is that, at each instant $t$, the increment $d X(t)$ of the earnings is a Gaussian random variable with mean $m(t) d t$ and variance $s(t) d t$. In addition, the increments of $X(t)$ over disjoint intervals are mutually independent, and we set $X(0)=0$. One calls $m(t)$ the drift at $t$, and $s(t)$ the volatility at $t$. The entrepreneur controls $a(t)=[m(t), s(t)]$ dynamically, but is constrained to choose $a(t)$ from some given set $A(Y(t))$. Finally, the entrepreneur's actions at each time $t$ must be conditioned at most on the history of earnings up to that instant.

Two remarks - one on withdrawals and the other on technology-are in order. First, an alternative requirement on the withdrawal process is that the "withdrawal rate" be bounded (and, nonnegative). This corresponds to ruling out lumpy withdrawals at any instant. We shall consider both cases, bounded as well as unbounded withdrawals, and analyse the latter by a limiting analysis of the former. Second, one should think of the sets of feasible mean-variance controls, $A(Y(t))$, as defining a technology correspondence.

13. For notational simplicity, we suppress the frm-specific index and write $k$, rather than $k_{i}$. Note too that $k$ can be zero. 
As capital stock accumulates, the firm has access to different investment opportunities ${ }^{14}$ These might include investing some of the earnings in the capital market itself (although we will place some restrictions on the firm's ability to do that).

Here is a more precise description of the model. Let $B(\cdot)$ be a standard Brownian motion (constant drift 0 and volatility 1 ), and let $F(\cdot)$ be the filtration generated by $B(\cdot)$. (See Karatzas and Shreve (1987).) A withdrawal is a stochastic process $W(\cdot)$ that is adapted to $F$, and is a.s. nondecreasing and right-continuous. A policy is a triple, $[m(\cdot)$, $s(\cdot), W(\cdot)]$, of stochastic processes, adapted to $F$, such that:

1. for every $t,[m(t), s(t)]$ is in $A(Y(t))$;

2. there exists a solution, $X(\cdot)$, adapted to $F$, of the equation,

$$
X(i)=\int_{0}^{t} m(u) d u+\int_{0}^{t} s^{1 / 2}(u) d B(u) .
$$

3. $W$ is a withdrawal, and for aII $t$,

$$
W(t) \subseteq y+X(t)
$$

It is known that $X$ is a.s. continuous, but in general its derivative does not exist at almost every $t$. Hence it is appropriate to talk about the accumulated earnings, but not the instantaneous flow of earnings.

As above, $T$ is the first time such that the capital stock, $Y(t)$, reaches or falls below zero. It follows from our assumptions and the continuity of $X$ that $Y(T)=0$, i.e. the capital stock is not allowed to overshoot and fall below the bankruptcy level, zero, when. the firm fails. Given the entrepreneur's policy, the failure time $T$ is a random variable (with the understanding that it may take the value infinity).

\subsection{The capital market: Individual firms and market equilibrium}

In this subsection we will give a brief description of the working of the capital market; a more elaborate discussion, that also addresses a number of related conceptual issues, may be found in Section 4 .

An entrepreneur approaches the capital market with a plan; a plan describes his withdrawal policy, $W(\cdot)$, his investment policy, $m(\cdot), s(\cdot)$, and, finally, his distribution policy, call it $D(\cdot)$. A distribution policy, simply put, is a description of what portion of the cumulated withdrawals the entrepreneur will turn over to his investors. Hence, the distribution policy is a non-decreasing stochastic process that satisfies the following constraint on all sample paths

$$
D(t) \leqq W(t), \quad t \geqq 0 .
$$

Investors as a group evaluate the expected present discounted value of any distribution policy. Assuming (as we will) that, investors are risk-neutral and identical, we can talk of the expected present discounted value to a representative investor; denote this value $G(y ; D)$, where $y$ is the initial capital stock. The rate of return for capital stock $y$ is then

$$
\frac{G(y ; D)}{k+y}
$$

14. A natural assumption to make is that $A(\cdot)$ is a monotonically increasing correspondence, i.e. that a larger set of opportunities is avajlable at a higher capital stock. Most of our results, though, do not require such ath assumption. 
Firms are price-takers in the capital market. If the market rate of return is $R$, an entrepreneur has to offer a distribution policy, and can expect an initial capitalization, such that

$$
\frac{G(y ; D)}{k+y}=R
$$

At rate $R$, an individual firm's demand for capital is the level $y$-and distribution policy $D$-that maximizes the entrepreneur's utility subject to the constraint (2.3). The equilibrium rate of return in the market is determined in the usual way; it is the rate that clears the capital market.

\subsection{Some simple examples}

For some simple technologies and withdrawal policies, it is possible to give an exact expression for the probability of survival, i.e. for the probability that a firm never goes bankrupt ( $T$ infinite).

Example 2.1. Suppose that the feasible control set $A$ is constant in the capital stock and, indeed, is a singleton; $A=\{m, s\}$. Withdrawals are made at a constant rate; $W(t)=$ wit, with $m_{1} s$, and $w$ strictly positive. The probability of survival is known to be

$$
P(y)= \begin{cases}1-\exp [-2(m-w) y / s], & \text { if } m>w, \\ 0, & \text { otherwise. }\end{cases}
$$

Thus, if $m>w$, then the probability of survival can be made arbitrarily close to 1 by starting with a sufficiently large initial capital stock. Note that the withdrawal policy has the feature of a perpetual bond with fixed coupon.

Example 2.2. Suppose that the feasible control set $A$ is constant (but not a singleton). Suppose also that the entrepreneur wants to choose a policy to maximize the probability of survival. It can be shown that the policy that is "optimal" in this sense is characterized by:

1. $W(t)=0$, all $t$, i.e. there are no withdrawals.

2. The drift and volatility are constant in time, say $m$ and $s$, respectively and the pair $(m, s)$ is chosen from $A$ to maximize the ratio, $m / s$.

The maximum probability of survival is, of course, given by (2.4), with $w=0$, and this optimal choice of $m$ and $s .{ }^{15}$

\section{PROFIT MAXIMIZATION AND OTHER BEHAVIOURS}

In this section we explore the implications of profit maximization in the context of the model. The main result is that profit maximization leads to failure with probability 1 ; indeed, the expected time to failure is finite. On the other hand, we show that many other behaviours lead to a positive probability of survival, including behaviours that generate

15. Under some additional restrictions, the result generalizes to the case where the technology correspondence varies with the size of capital stock. Pestien and Sudderth (1988) show that the optimal survivalist policy is to pick $m$ and $s$ to maximize, at every $Y(s)$, the mean-variance ratio, among the pairs available in $A(Y(t))$. 
positive profits, provided that the firm is sufficiently productive. (In fact, such behaviour was illustrated in the first example of Section 2.3).

To make these inferences precise, we must first fix on a definition of "profit." A natural first proposal might be to equate profit with earnings. Since earnings during any interval of time are stochastic, and earnings accrue through time, we need an appropriate aggregate that accounts for these two features. Addressing the second feature first, we anticipate Section 4 by assuming that there is a market rate of interest (independent of the maturity), and that earnings at future dates are discounted at that rate. Thus, the overall measure of profit would be the present value of the eamings flow, discounted at the market rate. To address the first feature, we propose to use the expectation of this present value, thus assuming risk neutrality in the definition of profit. ${ }^{16}$

It is easy to see that maximization of the expected present value of earnings implies that withdrawals will be zero, since this leads to the longest possible time to failure, but has no influence on the earnings. Thus profit maximization in this sense leads to the conclusion that investors never realize any return on their investments, a conclusion that we find unacceptable.

We are thus led to propose a definition of profit that substitutes withdrawals for earnings in the above definition. In other words, we shall define profit to be the expected total discounted withdrawals, namely

$$
E\left\{\int_{0}^{T} \exp (-r t) d W(t) \mid Y(0)=y\right\}
$$

where $r$ is the market rate of interest. Note that in the definition of profit, withdrawals are zero after the failure time, $T^{17}$ A profit maximizing entrepreneur therefore maximizes (3.1) subject to technological and market constraints. ${ }^{1.8}$

\subsection{A simple result on firm failure}

The main result of this section takes its simplest form, and admits of a closed-form solution in the special case in which the entrepreneur has no choice of drift and volatility, i.e. the set $A$ contains a single point, say $(m, s)$. Thus, in this case, the entrepreneur can control the withdrawal process, but not the evolution of earnings. We shall see that the optimal withdrawal process, ie. the process that maximizes (expected present value of profit, takes a special form, which we call a barrier process (following Harrison (1985)). Heuristically speaking, $W$ is a batrier process with barrier $b$ if the flow of withdrawals is zero as long as the capital stock remains below $b$, and is regulated so as to keep the capital stock from rising above $b$. Formally $W$ is defined by

$$
W(t)=\sup \left\{[X(s)+y-b]^{+}: 0 \leqq s \leqq t ;\right.
$$

16. Of coutse, expected present value is the standard measure used in economics to deal with uncertainty and time. For the purposes of market selection it is also the appropriate measure (see Footnote 6).

17. Note that, although $W$ need not be differentiable, the stochastic integtal (3.1) will exist for any policy that satisfies the conditions of the previous section.

18. W( $)$ is the total withdrawal from the enterptise; part of this withdrawal is paid to the investors and the remainder accrues to the agent. A profit-maximizing entrepreneur actually maximizes the present value of his portion of the withdrawals subject to the requirement that the withdrawals paid to his in pestors gives them a competitive return (see Section 4 for further details). Since the agent and his investors are both risk-neutral, with a common interest rate $r$, this constrained aptimization problem is equivalent to the maximization of the total withdrawal (3.1). Capital market equilibrium then determires what fraction of this total surplus accrues to investors. 
where for any number $z, z^{+}$denotes the maximum of $z$ and 0 . It is clear from the definition that, with such a withdrawal policy the capital stock is always between 0 and $b$. What is not so obvious, is that for any barrier policy,

$$
E(T \mid Y(0)=y)<\infty \text {; }
$$

the weaker results that failure occurs eventually, with probability 1, i.e. Prob $(T<\infty)=$ 1 , is well known.

Let $V^{*}$ denote the value function for the problem of maximizing profits, i.e. maximizing (3.1) over all feasible withdrawal policies.

Theorem 3.1. Suppose that $A$ consists of a single point, $(m, s)$, and that $m, s$, and $y$ are all strictly positive. Then there exists a barrier withdrawal process, with barrier $b^{*}$, that is optimal among all withdrawal policies. Furthermore, the value function $V^{*}$ is $C^{2}$, concave and strictly increasing, and:

1. $V^{*}(0)=0$, and $\mathrm{V}^{* \prime}\left(b^{*}\right)=1$;

2. $V^{*}(y)$ is strictly concave for $y$ between 0 and $b^{*}$;

3. $V^{*}(y)=V^{*}\left(b^{*}\right)+\left(y-b^{*}\right)$ for $y>b^{*}$.

Finally, the expected time to failure, under the optimal withdrawal policy, is finite.

The intuition for the result that a barrier policy is optimal is the following: a withdrawal at rate $w$ yields a marginal benefit of $w d t$ at any instant. At the same time this withdrawal lowers the level of capital stock and therefore the associated value; over an "instant" this loss in value can be linearized and equals $w V^{\prime}(y(t)) d t$. The net benefit therefore is $w\left[1-V^{\prime}(y(t)] d t\right.$. The optimal withdrawal is hence 0 or the maximum permissible as $V^{\prime}(y)>1$ or $<1$. Once the value function is proved to be concave, the optimality of a barrier policy follows. ${ }^{19,20}$

The intuition for the result that the expected time to failure is finite for a barrier policy may be understood by a discrete-time analogy. The capital stock is a Markov process, and given that it is at level $b$, there is a positive probability that it reaches 0 before it returns to $b$. Call a "cycle" a pair of times, $t$ and $s$, such that the capital stock equals $b$ at time $t$, and $s$ is the next time at which it equals $b$ again ( $s$ may be $t+1$ ). The number of cycles before failure then has a geometric distribution.

\subsection{A general result on firm failure}

We turn now to the general case in which the entrepreneur controls the earnings as well as the withdrawal process. Recall that his ability to do so is constrained by the technology correspondence $A(\cdot)$; in particular, at $Y(t)$, the mean-variance control, $[m(t), s(t)]$, has to be chosen to satisfy $[m(t), s(t)] \in A(Y(t))$. We make the following assumptions on the tecnology correspondence:

T1 The technology correspondence is compact-valued, i.e. $A(z)$ is a compact set for every $z \in \mathbb{E}$, , and has a non-empty intersection, i.e. there is $(m, s), m>0$, such that $(m, \hat{s}) \in A(z)$ for every $z \in \mathbb{R}_{+}$.

19. It is interesting to note that the concavity in the value function is entirely driwen by bankruptey; the marginal insutance value of higher capital stock decreases in $y$. In particula', it can be shown that the value function is concawe regardless of the curvature properties of the instantaneous utility function.

20. In a related discrete-time model, Shubik and Thompson (1959) had shown that a barrier policy is optimal. See also Radner-Shepp (1996). 
T2 There are no riskless actions, i.e. for every $(m, s) \in A(z), s>0$. This is true for every level of capital stock $z \in \mathbb{R}_{+}$.

T3 Technology is subject to decreasing retums. Denoting the maximum earnings drift by $\tilde{m}(\cdot)$, i.e. denoting $\tilde{m}(z) \equiv \max \{m \mid(m, s) \in A(z)\}$, the following holds:

$$
\tilde{m}(z+\varepsilon)<\tilde{m}(z)+r \varepsilon,
$$

where $r$ is the rate of interest. Furthermore, $\tilde{m}(\cdot)>0$.

For the results that characterize the optimal withdrawal policy, (T1)-(T3), together with a reduced-form assumption that we present later, will suffice. We will also present a complete characterization of the optimal mean-variance policy. For the first part of that characterization (T1)-(T3) again suffices. A second part of that characterization is a monotonicity result and for that result we need to assume that the technology correspondence, is increasing in $z$ and that the mean-variance efficient frontier is strictly concave, for every fixed $z$.

For every variance $s$ that can be feasibly chosen at capital stock $z$, denote the maximum corresponding mean by $g(s, z)$, i.e.

$$
g(s, z) \equiv \max \{m \mid(m, s) \in A(z)\} \text {. }
$$

Of course, $g(\cdot, z)$ is defined over the projection, $B(z) \equiv\{s \mid \exists m$ such that $(m, s) \in A(z)\}$. Suppose that $B(z)$ is an interval. The required assumptions are:

T4 The technology correspondence is monotone; $z^{\prime}>z$ implies $A\left(z^{\prime}\right) \rightleftharpoons A(z)$.

T5 The function $g$ is $C^{2}$ on its domain. Furthermore, $g(;, z)$ is strictly concave for every fixed $z, z \geqq 0$ and $s g_{12}(s, z) \geqq g_{2}(s, z), z \geqq 0$.

Assumptions (TI)-(T4) are standard; most of (T5) is also standard. The non-standard requirement is $s g_{12} \geqq g_{2}$, and this is an assumption about the concavity of the marginal drift, $g_{1}$.

The last assumption is a reduced form assumption on twice differentiability of the value function $V^{*}$. Recall that we allow unbounded withdrawal rates in our problem. Since the setting is continuous time, it is useful to also consider the case where the rate of withdrawal cannot exceed some upper bound, say $\bar{w}$; denote the associated value function $V^{*}(\cdot ; \bar{w})$. The full description of the reduced form assumption is:

$\mathbf{R}$ There exists a sequence of upper bounds, $\bar{w}_{n}, n=1,2, \ldots$, converging to infinity, with the property that the associated value functions $V^{*}\left(\cdot ; \bar{w}_{n}\right)$ are $C^{2}$. Furthermore, the value function for the unbounded withdrawal problem, $V^{*}$, is $C^{2}$ as well.

Two comments about this assumption are worth making. First, this is essentially an assertion that there exists a solution to the profit maximization problem. It can be shown, for instance, that if $V^{*}(\cdot ; \bar{w})$ is $C^{2}$ then it solves a Bellman equation (see (A.29) in the Appendix for detajls) and hence that there exists a stationary optimal withdrawal and mean-variance policy (that is given by a selection from the Bellman correspondence). Conversely, if there exists a stationary optimal policy satisfying certain minimal properties, then its payoff function (the value function $V^{*}\left(\cdot ;\right.$ wi)) can be shown to be $C^{12}$. Making the assumption directly avoids a long existence argument. Second, there are two primitive conditions under which assumption $\mathbf{R}$ is known to hold, i.e. under these conditions $\mathrm{R}$ is not an assumption but rather is a conclusion. The first condition is that the

21. For example, if the optimal withdrawal policy is piecewise continuous and the optimal mean-variance policy is continuous, then Krylow $\left(1980\right.$, Theorem 1.4.6) can be used to show that $V^{*}\left(-; w^{\prime}\right)$ is $C^{2}$. (A similar argument is developed in full detail in Dutta (1994), 
technology correspondence is a constant correspondence, i.e. $A(z)=A$, for some compact strictly convex set $A$ (see Lemma 3.3 below). The second set of conditions is given by Radner (1996) who shows how one can construct the value functions $V^{*}(\cdot ; \bar{w})$ from the solutions to a pair of one-dimensional ordinary differential equations.

The main theorem of this section is:

Theorem 3.2. Suppose that assumptions (T1)-(T3) and (R) hold. Then,

Withdrawal policy. The optimal withdrawal policy is stationary and of the barrier type. There is a critical level of capital stock $b^{*}$ such that it is optimal for a profit-maximizing entrepreneur to withdraw nothing at levels of capital stock below $b^{*}$, and to withdraw instantaneously down to $b^{*}$ if the capital stock exceeds this optimal barrier level.

Mean-Variance Policy. The optimal mean-variance policy is stationary, i.e. is of the

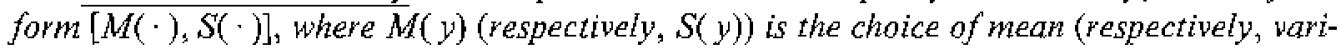
ance) at capital stock $y$. Furthermore, the chosen mean is the maximum feasible for that variance, i.e. $M(y)=g(S(y), y)$. Finally, at zero capital stock the mean-variance ratio is maximized, while at the barrier, the mean is maximized. In other words,

$$
\begin{aligned}
\frac{M(0)}{S(0)} & =\max \left\{\frac{m}{s} \mid(m, s) \in A(0)\right\}, \\
M\left(b^{*}\right) & =\max \left\{m \mid(m, s) \in A\left(b^{*}\right)\right\} .
\end{aligned}
$$

Value Function. The value function satisfies the same conditions as in Theorem 3.1.

If, in addition, assumptions (T4) and (T5) hold, and $S(0)$ is interior, then the meanvariance policy is also monotone; $y^{\prime}>y$ implies $M\left(y^{\prime}\right) \geq M(y)$ and $S\left(y^{\prime}\right) \geq S(y)$. The functions $M(\cdot)$ and $S(\cdot)$ are, additionally, continuous.

Two corollaries of the main theorem are particularly interesting. The first relates to the case of a constant technology, i.e. to the case where there is a set $A$ such that $A(y)=$ $A$, for all $y \in \mathbb{R}+$. This would be the appropriate case if unspent earmings simply accumulate as (uninvested) cash reserves.

For the constant technology case all of the assumptions, (T1)-(T5), are automatically satisfied provided $A$ is a compact, strictly convex set. In this case one can directly show: ${ }^{22}$

Lemma 3.3. The walue functions for the bounded as well as the unbounded withdrawal cases, $V^{*}$ and $V^{*}(\cdot ; \bar{w})$ are $C^{2}$ (in the latter case for any upper bound $\bar{w}$ ).

It then follows that we have:

Corollary 3.4. In the constant technology case, the conclusions of Theorem 3.2 hold as long as the technology set $A$ is compact and strictly convex. ${ }^{23}$

In each of these two cases, decreasing returns or constant technology it also follows that a profit maximizing entrepreneur will fail almost surely. Indeed, his expected time to failure is finite.

22. The proof of Lemma 3.3 can be found in Dutta and Radner (1998)

23. The careful reader may note that our assumption on $A$ does not imply that its upper envelope $g(s)$ is differentiable - an assumption we needed in. Theorem 3.1. It turns out that we do not need this assumption any longer for the constant technology case. 
Corollary 3.5. Regardless of the level of initial capital stock, a proft maximizing entrepreneur's expected time to fallure is finite.

Recall from Example 2.2 that the policy that maximizes the probability of survival is a constant choice of $\left(\hat{m}_{3}, \hat{s}\right)$ and zero withdrawal. Theorem 3.2 makes the (intuitive) point that a profit-maximizing entrepreneur behaves the same way when the capital stock is (close to) zero. As the capital stock increases, the agent picks higher mean (and variance) actions; around the barrier he behaves as if there were no bankruptcy. He picks the highest drift available, and withdraws cash at the maximum rate, i.e. instantaneously draws it down to $b$ if it ever exceeds that level.

One important difference between the proofs of Theorems 3.1 and 3.2 is worth remarking on. Theorem 3.1 is proved by construction; we solve for the present discounted value of a barrier policy and then prove, by way of a verification lemma, that a particular barrier policy is, in fact, the globally optimal policy. This is no longer possible when $(m, s)$ can be varied as well; their choice depends in a non-linear way on the level of capital stock and closed form solutions are no longer available. The method of proof which we employ is purely analytical; we establish that the value functions for the bounded withdrawal problem converges to the value function for the unbounded problem and the latter solves the appropriate Bellman equation for the unbounded problem. We then show that this value function has the properties asserted in the theorem.

\section{THE CAPITAL MARKET}

We have seen that profit maximization leads to failure in finite time, but is it possible that, if entrepreneurs must compete for investment funds, only profit maximizers will obtain financing? After all, the required return to investment funds should be considered endogenous, and it is conceivable that the equilibrium required return would drive out of the investment-funds market entrepreneurs who do not maximize profits. In fact, the answer to this question depends on what one assumes about the "competitive environment" of the entrepreneurs. We shall see that, if the distribution of the productivity of potential firms is sufficiently "dispersed," then, in equilibrium, entrepreneurs in firms with higher than the "marginal" potential productivity can obtain financing even if they do not fully maximize profits. We shall also see that if capital is entirely liquid then, again, there will be intra-marginal firms whose entrepreneurs can obtain financing without fully maximizing profits.

\subsection{Financing an individual firm}

In this subsection we will discuss the determinants of the demand for investment funds. Suppose that, at time 0 , a cohort of investors and a cohort of agent/entrepreneurs enter the market. We first describe the entrepreneurs. Each entrepreneur is endowed with a technology correspondence $A(\cdot)$, as in the model of Section 2. In order to start the firm's operations, the entrepreneur must make an investment that costs $k$ dollars, $k \geq 0$. In addition, the entrepreneur seeks to start with an initial capital stock $y, y \geq 0$. Thus the total investment is $(k+y)$. The entrepreneur chooses a policy, $[m(\cdot), s(\cdot), W(\cdot)]$, as in Section 2 , and also chooses a distribution policy, $D(\cdot)$, which is a stochastic process with the same properties as the withdrawal process, $W(\cdot)$, but subject to the additional constraint,

$$
D(t) \leqq W(t), \quad \text { all } t .
$$


As discussed in Section 2.2, we interpret $D(t)$ as the accumulated amount of withdrawals that have been given to the firm's investors up to time $t$. The quintuple $[y, D(\cdot), m(\cdot)$, $s(\cdot), W(\cdot)]$, will be called the entrepreneur's plan. Note that $A(\cdot)$ and $k$ are exogenously given for the entrepreneur, whereas the plan is chosen. In principle, $A(\cdot)$ and $k$ can vary over the cohort of entrepreneurs.

An investor in a given firm receives a fraction of the distribution process in proportion to the size of his investment. Suppose we assume that each investor is risk-neutral, has stationary preferences with regard to the "flow" of returns received from the firms in which he has invested, and has a positive degree of impatience. Even with these strong assumptions about investors, the equilibrium of the investment market can be quite complex. We therefore make the "representative-investor" assumption that all the investors have the same subjective rate of discount; denote this common rate by $r$. It follows that, in equilibrium, there will be a single market rate of interest, equal to $r$, the same for all maturities. It also follows that each investor will invest only in firms that give him the maximum return per dollar of investment. ${ }^{24}$

In equilibrium, all firms that are actually financed will therefore offer the same return; we shall call this return the equilibrium rate of return. As in Section 3, for a given firm let $V^{*}(y)$ denote the maximum profit if the initial capital stock is $y$, where profit is calculated as in (3.1), with $r$ the equilibrium rate of interest. The firm will be able to offer a distribution process that meets or exceeds the equilibrium rate of return if and only if

$$
R^{*} \equiv \max _{y} V^{*}(y) /(k+y)
$$

is at least as large as the equilibrium rate of return. In this case, the entrepreneur will be forced to maximize profits in order to obtain financing only if $R^{*}$ is exactly equal to the equilibrium rate of return. We might call $R^{*}$ the potential rate of retum of the firm ${ }^{25}$

The demand function for investment funds by profit-maximizing entrepreneurs, is easily derived. Suppose the market rate of return is $g$ and let the firm's potential rate of return be $R^{*}>g$. If total investment in the frm is $k+y$, then the entrepreneur is constrained to offer a distribution policy, $D$, whose expected present value is at least $g \cdot(k+y)$. A profit-maximizing entrepreneur will choose the initial capital stock $y$ to maximize

$$
\max _{y \geq 0} V^{*}(y)-g \cdot(k+y)
$$

It follows from Theorem 3.2 that the optimal $y$ is the solution of the first-order condition,

$$
V^{* \prime}(y)=g
$$

and that this solution is strictly decreasing in $g$.

\subsection{Market equilibritum}

The equilibrium rate of return will be determined in the usual way, as the rate at which the supply of investment funds by investors equals the demand by entrepreneurs.

The aggregate demand for investment funds at a rate $g$ is, of course, the sum of individual firms' demands at that rate. We have already indicated how this demand is

24. We consider the capital market as being open only at period 0 . This is without loss of generality; since all investors have the same information and identical preferences, there will be no further activity in the capital matket after period 0 . (See also the related discussion in Footnote 28).

25. Note that $R^{*}$ is well-defined given the properties of the value function that we established in Theorem 3.2. Note also that if the size of sunk capital $k$ is zero, then the potential rate is realized at $\mu=0$. 
determined for a firm that is run by a profit-maximizing entrepreneur. For non-profit maximizing entrepreneurs that determination is qualitatively similar; it is the level of capital stock $y$ that maximizes the entrepreneur's utility ${ }^{26}$ subject to the constraint that the risk-neutral investor's rate of return be at least $g$.

On the supply side we place no real restrictions. The only assumption that we do need is that there is an equilibrium, i.e. that there is a rate $g$ at which the market clears. Let $R^{* *}$ denote the maximum value of $R^{*}$ in the population of firms. It is important to distinguish two cases, according to whether $R^{* *}$ does or does not exceed the equilibrium rate of return, $g$.

\section{Case 1. $g<R^{* *}$.}

In this case there will be firms that can be financed whose potential rate of return strictly exceeds $g$. As we shall show below, such firms bave the option of not maximizing profits and obtaining a positive probability of survival. We shall argue below that this is the "normal" case.

\section{Case 2. $g=R^{* *}$.}

In this case, all firms that are financed must maximize profits, and hence will eventually fail.

Case 1 would obtain if the total supply of investment funds exceeded the total demand of firms whose potential rate is $R^{* *}$, but there were some firms with a lower potential rate. This would be the case if there were many firms, but the distribution of $R^{*}$ was sufficiently "dispersed" (for example, no two firms had exactly the same $R^{*}$ ).

Another sufficient condition for the market rate to be less than $R^{* * *}$ is for all capital to be liquid, i.e. for $k=0$. In this case each firm's potential rate is realized at $y=0$. In particular, therefore, every one of the firms whose potential rate is $R^{* *}$ will demand, at that rate, zero amount from the capital market. Consequently at a rate of return equal to $R^{* *}$ there will necessarily be an excess supply of investment funds.

On the other hand, Case 2 could obtain if the total demand of firms with potential rate equal to $R^{* *}$ were at least as large as the total supply of investment funds (for example, if there were enough profit-maximizing firms with $R^{*}=R^{* *}$ ).

Collecting all this together we have the following result:

Proposition 4.1. Suppose that either of the following two conditions hold. Either:

1. The potential rate of retum is dispersed in the sense that a zero mass of firms have a potential rate equal to the maximum potential rate $R^{* *}$; or,

2. All capital is liquid, i.e. $k=0$.

Under either of these two conditions, the equilibrium rate of retwn will be less than $R^{* *}$. In particular at the equilibritum rate $R^{*}$, there will be supra-marginal fims whose potential rate of return is strictly higher than $R^{*}$.

We consider that it is realistic to suppose that one of two conditions of Proposition 4.1 will be satisfied. In this case, only the "marginal" firms that obtain financing will be

26. For instance, a pure survivalist entrepreneur has a utility function that is given by $E \int_{0}^{T} e^{-\rho t} r d t=1-E e^{-\rho T}$. In the limit, as $\rho \rightarrow 0$, this utility futuction becomes $P(T=\infty)$. 
forced to maximize profits, whereas the "supramarginal" firms will have the freedom to choose other behaviour. After a long elapsed time, the vast majority of surviving firms will exhibit behaviours that lead to a positive probability of surviving forever, provided that originally there was a positive mass of such firms. In particular, most of the profitmaximizing firms will have failed. ${ }^{27}$

\subsection{Entrepreneurs who survive}

It remains to show that, if $R^{* *}>g$, then there are behaviours that enable the entrepreneur to provide the investors with an expected rate of return $g$, and still have a positive probability of survival. We shall give one example of such behaviour; it will be clear that there are many others.

Example 4.2. Roughly speaking, the "survivalist" policy in this example mimics the profit-maximizing policy up until the time the profit-maximizing firm would fail, except that the entrepreneur withdraws no compensation for himself; thereafter the entrepreneur follows the policy of Example 2.1, with fixed mean-variance $\left(\hat{m}_{1} \hat{s}\right)$ and a fixed withdrawal $\hat{w}<\hat{m}, \hat{w} \geqq 0$. Let $y^{*}$ be the initial capital stock that corresponds to the potential rate of return of the firm, $R^{*}$, i.e. that attains the maximum in (4.2), and let $X^{*}, Y^{*}$, and $W^{*}$ be the stochastic processes of accumulated earnings, capital stock, and accumulated withdrawals, respectively, that are generated by the profit-maximizing policy of Theorem 3.2 , with initial capital stock $y^{*}$. In addition, let $T^{*}$ be the corresponding failure time. Let $f$ be defined as the ratio $g / R^{*}$, and define the distribution process $D^{*}$ by $D^{*}(t)=f W^{*}(t)$, for $t<T^{*}$. It follows that the distribution process $D^{*}$ yields a gross return

$$
f V^{*}\left(y^{*}\right)=g V^{*}\left(y^{*}\right) / R^{*}=g\left(k+y^{*}\right),
$$

to the investors in the firm, and hence a rate of return of $g$. Now modify the profitmaximizing policy by changing the withdrawal process to be

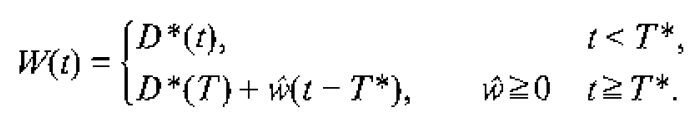

Finally, modify the control of the drift and volatility as follows. Let $M^{*}$ and $S^{*}$ denote the profit-maximizing policy functions of Theorem 3.2 , and, recall that $(m, s)$ is the meanvariance pair that belongs to $A(z)$, for all $z \in \mathbb{R}+$. Let

$$
\begin{aligned}
& m(t)= \begin{cases}M^{*}\left[Y^{*}(t)\right], & t \geqq T^{*}, \\
\hat{m}, & t>T^{*},\end{cases} \\
& s(t)= \begin{cases}S^{*}\left[Y^{*}(t)\right], & t \leq T^{*} \\
\hat{S}_{1} & t>T^{*}\end{cases}
\end{aligned}
$$

This policy yields the profit-maximizing earnings process up to time $T^{*}$, so the withdrawal process (4.6) is feasible. Note that after the time $T^{*}$ the process is the same as that of Example 2.1 provided the constant withdrawal rate $\hat{w}<m$. The modification $(4.6)-(4.7)$ will, of course, change the capital stock process and the failure time to, say, $Y$ and $T$, respectively. It is easy to see that, with the new policy, the firm will survive with positive

27. A similar conclusion would seem to follow if investor preferences are dispersed. If investors have different attitudes towards risk then it seems likely, again, that fims other than those run by profit-maximizing entrepreneurs, will be financed. 
probability. Since the (expected) profit of the firm is positive, there is a positive probability that $W^{*}(t)$ becomes strictly positive for some time strictly less than $T^{*}$, ie. before the profit-maximizing firm would fail; for the moment, call this event $P$. In event $P$, between that time and $T^{*}, W(t)<W^{*}(t)$, and hence $Y(t)>Y^{*}(t)$, and in particular, $Y\left(T^{*}\right)>0$. It can be shown that conditional on event $P$, the probability that $T$ is infinite is positive, (by way of Example 2.1). Hence the unconditional probability is also positive.

We note that the above modified policy is not "stationary" in the sense of (3.4), since the entrepreneur must keep track of $Y^{*}(t)$ rather than $Y(t)$ up to time $T^{*}$. We also note that the modified policy could be further modified in many ways that would still yield a positive probability of survival. For example, after reaching time $T^{*}$, the entrepreneur could pursue any policy of the type in which $m[Y(t)]>0$ and $W(t)=\int_{0}^{t} w[Y(s)] d s$, with the rate $w[Y(s)]<m[Y(s)]$.

It would be interesting to characterize a policy that maximizes the probability of survival, subject to the constraint that the firm's investors receive the market rate of return. The solution to this problem is not known to us.

\section{ENTRY}

Up to now, we have discussed a single cohort of potential new firms and a single cohort of investors. We now sketch what happens if there are successive cohorts of potential firms competing for new investment funds. For this analysis, it is convenient to take the times at which successive cohorts arrive to be discrete, rather than continuous. Furthermore, to appreciate the stochastic aspect of the process, it is appropriate to recognize explicitly that there are finitely many firms in each cohort. We shall see that, roughly speaking, if in every cohort there are firms that are financed that have a positive probability of surviving forever, then after a long time a negligible fraction of firms will be profit-maximizers.

Accordingly, consider an infinite sequence of (integer) dates, $t$, starting at $t=0$, and suppose that at each date a new (finite) cohort of potential firms becomes available, and likewise a new (finite) supply of investment funds. In the simplest case, which is the only one that we discuss here, the successive cohorts are identical, and the supply function of new funds is the same at all dates. At each date the new firms compete in the capital market, but there is no further trading in securities of the existing firms. ${ }^{28}$ Thus, at each date the situation described in Section 4 is repeated, and identical populations of firms are financed at the same equilibrium market rate of return. Note that, once a firm is started, it evolves in continuous time, but we only look at the process at the integer times.

In cohort $t$ some number of firms will turn out to be "immortal," i.e. will survive forever; let the number of these be denoted by $I(t)$. The random variables $I(t)$ are independent, identically distributed, and nonnegative. We suppose that the expectation of $/(t)$ is strictly positive; denote this expectation by $l>0$. (In other words, in every cohort there is at least one firm that is sufficiently productive to be financed, but chooses behaviour that yields a positive probability of being immortal.) The remaining firms in each cohort are "mortal." In particular, by Theorem 3.2, profit-maximizing firms will be mortal.

28. The assumption that there is no further trading is, again, without loss of generality. At date $t_{\text {, suppose }}$ that an investor could either buy shares of an existing firm or those in a start-up. Existing shares will trade at value, i.e. a dollar will trade for a dollar whereas new shares will generate a rate of retura $\geq 1$. Hence, only new shares will be traded. 
Let $J(t)$ be the total number of immortal firms at date $t$ (an integer), i.e..$^{29}$

$$
J(t)=I(1)+\cdots+I(t) .
$$

It is clear that the expected value of $J(t)$ is equal to $t l$. Indeed, by the strong law of large numbers, $J(t) / t$ will almost surely approach $l$, as $t$ increases. In particular, $J(t)$ will increase without bound as $t$ does, and "more or less" linearly.

On the other hand, suppose that each cohort contains some positive number of profitmaximizing firms, and let $P(t)$ denote the total number of profit-maximizing firms in existence at date $t$. It can be shown that $\{P(t)\}$ is ergodic, and that the sequence of averages,

$$
[P(1)+\cdots+P(t)] / t
$$

converges a.s. to some constant. In fact, let $T_{i}^{*}$ denote the length of life of the $i^{r}$-th profitmaximizing firm in a cohort; then by Little's Theorem (see, e.g. Whitt (1991)), this constant is

$$
\sum_{i} E T_{i}^{*} \text {. }
$$

(Note that, by Theorem $3.2, E T_{i}^{*}<\infty$.) It follows by an elementary argument that $P(t) / t$ converges a.s. to 0 .

Putting the last two paragraphs together, we conclude that

$$
\frac{P(t)}{J(t)}=\frac{P(t) / t}{J(t) / t}
$$

converges a.s. to $(0 / l)=0$.

\section{CONCLUDING REMARKS}

In the context of our particular model of the firm and the capital market, we have shown that maximization of profit leads, almost surely, to eventual failure, whereas other feasible behaviours have a positive probability of surviving forever. Furthermore, firms with a sufficiently high potential rate of return will be able to compete effectively for investment funds, even if they are not profit maximizers.

One implication of our analysis is that, in the presence of uncertainty and bankruptcy, the size of retained earnings matters because it provides insurance against a string of losses. A profit-maximizing entrepreneur does care about this insurance feature of retained earnings, weighs it against the implied loss in profits, and then tries to steer his enterprise towards an optimum size given by the barrier $b^{*}$; in the presence of uncertainty this is impossible to do forever. On the other hand, entrepreneurs who care directly about survival will accumulate larger capital stocks.

In conducting our analysis we departed from "perfect competition" in two important ways. First, firms go bankrupt if they accumulate sufficiently high losses. Second, firms are not identical in their profit opportunities, or at least the most productive firms cannot be infinitely replicated ${ }^{30}$ Although we consider the empirical validity of these two "facts" to be self-evident, as even a casual inspection of the real world teveals, it may nevertheless

29. Note that $J(t)$ is a lower bound on the number of firns, at date $t$.

30. The Iatter restriction is not needed it capital is fully liquid, recal Proposition 4.1. 
be instructive to see what happens to our results without these two assumptions. Endogenizing bankruptcy would, most likely, complicate but not qualitatively change the conclusions. A similar conclusion holds if the most productive technologies can be imitated but with some lag.

In this final section we explain these two assertions, together with discussions of questions that we would like to answer, but have not yet.

\subsection{Bankruptcy}

In our model thus far there is no explicit reason why investors would stop funding an entrepreneur - i.e. would let him go bankrupt - even if he has run up arbitrarily bigh losses. We will now present such a reasoning based on costly refinancing.

Note first that the bankruptcy liquidation value need not be zero, i.e. it need not be the case that $V^{*}(0)=0$. This is what we have assumed so far but we can easily relax this assumption. Suppose that $V^{*}(0)>0$. The optimization problem faced by a profit maximizing entrepreneur is

$$
\operatorname{Max} E \int_{0}^{T} e^{-r \cdot s} d W(s)+E e^{-r T} V^{* *}(0) .
$$

Clearly this optimization problem can be rewritten as

$$
\operatorname{Max}\left\{E \int_{0}^{T} e^{-r s}\left[d W(s)-r V^{*}(0)\right]\right\}+V^{*}(0) .
$$

In other words, the optimization problem with positive liquidation value is exactly the same as the optimization problem with zero liquidation value and per period returns equal to $d W(s)$ plus a constant. It is not difficult to show-and should arrive as no surprisethat the optimal policy for this problem is also a barrier policy. Hence, even in this case, profit maximizing entrepreneurs will fail in finite time almost surely.

The size of the liquidation value $V^{*}(0)$, should of course be endogenously determined; it will depend both on the costs of refinancing $c_{i}$ (where such costs include legal fees, financial advisers' fees, costlier financial terms, etc.) and on the scrap value $v_{i}$ of the firm's assets (such as the sunk capital). Here is a sketch of how our model can be enriched in order to derive this value endogenously.

First, a competitive firm takes the liquidation value as a given; call this value $\theta_{i}$. $\mathrm{A}$ profit-maximizing firm then maximizes (6.I)-with $\theta_{i}$ replacing (the yet to be determined) $V^{*}(0)$. (Likewise, a non-profit-maximizing firm maximizes its utility function attaching an appropriate weight to the liquidation value.) Each of these optimization exercises yields, as in Section 4. I, a market demand function for investment.

Second, as in Section 4.2, capital market equilibrium will be determined at a rate of return $g$ at which aggregate demand for investment funds equals aggregate supply. Additionally, and this is new, it must be the case that every financially distressed firm chooses the better of the two options-refinancing or scrapping, i.e.

$$
\theta_{i}=\max \left(V^{*}\left(y^{*}\right)-c_{i}, v_{j}\right)
$$

where $y^{*}$ is the demand for investment funds at rate $g$. Of course, at such an equilibrium, $\theta_{i}=V^{*}(0) .^{31}$ Our previous analysis is a special case of the preceding discussion with infinite costs to refinancing and a zero scrap-value.

31. To keep the notation consistent, we continue to write $V^{*}(0)$ without a subscript for firm $i$ but it should be clear that this liquidation value is in tact firm dependert, just as Equation (6.1) says. 
Even when refinancing costs are finite, the analysis and conclusions will be similar One way to see this is to note that either of two things will happen to a profit maximizing entrepreneur who gets funded: either his refinancing costs are high enough that he will choose to scrap the assets upon bankruptcy or he will refinance after every distress (and, by the above argument, distress is a probability one event for such an entrepreneur). In the former case, the conclusions are completely unchanged. In the latter case, the firm will survive but with an infinite number of refinancings. And now if one adds a little bit of realism-that the refinancing costs might increase from distress to distress-then under an obvious condition the entrepreneur will eventually prefer scrapping the asset. And then we are back to the main conclusion on survival-in the long-run the fraction of profit maximizing entrepreneurs in the market will tend to zero.

It is important to note that there are yet other reasons why firms go bankrupt, reasons that do not have anything to do with refinancing costs. One set of reasons is incentivesrelated; if the shareholders in a firm have less information than the entrepreneur about the latter's actions or quality, then they might structure an incentive scheme under which the entrepreneur-and his technology-are let go after an appropriate amount of losses. Radner (1986) and Dutta and Radner (1994a) show that such an incentive scheme is asymptotically efficient, for both shareholders as well as the entrepreneur, as discount rates approach zero. In that context the current results show that, faced with such an. incentive scheme, profit-maximizing entrepreneurs will (make withdrawals according to a barrier policy and will) necessarily be let go, and they will asymptotically disappear from the population of all entrepreneurs.

\subsection{Imitation and replication}

In the model (with positive sunk costs) it is assumed that firms are heterogeneous and the most productive firm canot be infinitely replicated. We now show that all that is required is that the most productive firm cannot be instantaneously infinitely replicated. Suppose that at time 0 there is a dispersion in available technologies, as modelled in Section 4. I, but the most productive technology can be imitated at cost by date $h$-where $h$ is any positive number. (The model studied thus far corresponds to $h=\infty$.)

The profit-maximizing value function for this model can be derived through the optimization exercise of Section 3-with the added proviso that there is a technological regime shift at date $h^{32}$ The potential rate of return is defined exactly as above (in (4.3)). Furthermore, it is clear that the heterogeniety in the time-interval $[0, h]$ implies that there will be a dispersion in the potential rate of return as well (although this dispersion will be tighter than in the case where $h$ is infinite). But some dispersion, however small, is all that is required for Proposition 4.1; since there is still a zero mass of firms clustered at the maximum potential rate of return, there will be some non-profit maximizing (yet productive) entrepreneurs who will get funded by the capital market. Over time, the profit maximizers will die....

The only case in which the market selection argument holds is if the most productive firm is infinitely and instantaneously replicable, i.e. if $h=0$. In that case no (profit maximizing) investor would ever put her money in a non-profit-maximizing entrepreneur's firm. ${ }^{33}$

32. In other words, the optimization will be done in two steps: first, the optimization starting at date $f t$ with the most productive technology, resulting in a value function, say $V^{* *}$. Second, the back ward induction step, optimization over $[0, h]$ taking $V^{\text {fay }}$ as the terminal payoff function.

33. The preceding discussion refers to a single cotort. Pursuing this line of thought in the context of a sequence of cohorts would naturally lead to a model with technical change, which is beyond the scope of this paper. Nevertheless, a realistic model of this type would exhibit a dispersion of productivity across fims. 


\subsection{Certainty}

It might appear that under certainty the market does select profit-maximizing behaviour, but this is not necessarily so. We explore this here briefly for the special case of a constant technology. The most straightforward way to reduce our model to one of certainty is to assume that $s=0$ for all $(m, s)$ in the set $A$. It is clear that an "efficient" entrepreneur will always choose the maximum drift in $A$; call this $m$ (which we may as well assume to be positive). In this case $W(t)$ is strictly less than $y+m t$, there is no insurance purpose to the cash reserve, and there is no maximum profit: the supremum, given the initial cash reserve, is

$$
V^{*}(y)=y+\frac{m}{r}
$$

In the interesting case where $m / r>k$, the potential rate of return is the supremum of

$$
\frac{y+m / r}{y+k}
$$

which is $R^{*}=m / r k$. If $R^{*}$ is strictly greater than the equilibrium market of return, then not all of the earnings need be distributed to the investors. From this point on the analysis parallels that of Section 5 .

The analysis of certainty brings out the simplicity of the model of the firm that underlies our analysis: It also highlights the productivity of the capital stock in the case of uncertainty.

\subsection{Extensions}

There are several directions in which our current analysis might be extended. First, it would be interesting to allow takeovers; in this case, the manager/entrepreneur can fail even if the firm itself is not in financial distress and in particular, this could occur if the entrepreneur over-accumulates assets. The relevant issue here is of course how costly it would be for shareholders to mount a takeover battle. These costs include not only the expenses associated with acquiring a large block of shares, proxy fights, etc, but also the loss of human, technological, and organizational capital vested in the current management. If these costs are high enough, then a takeover will not be profitable, and even for a middle range of costs, the threat of a takeover may constrain the over-accumulation of assets but may not entirely eliminate it.

Second, it would be useful to allow for more than one kind of capital stock. For instance, one could imagine the capital stock to be a vector each of whose coordinates measure the productive capacities of different projects. In this case an entrepreneur would have to make a decision about how to divide current earnings among withdrawals, expenditures on different projects, and additions to cash reserves. The advantage of this formulation is that it would allow for a richer description of firm dynamics.

Third, we would like to examine competition in the product market (in addition to the competition in the capital market analysed thus far). We have some preliminary analysis of this issue; our results suggest that competition does not guarantee that profit maximizers will survive at the expense of the others nor does it guarantee failure with probability one. 


\subsection{Related literature}

Market rationality has been examined in the evolutionary analyses of Winter (1987) and Nelson and Winter (1982). Our analysis of the hypothesis departs from that of Nelson and Winter in two basic ways. First, they believe that non-profit-maximizing firm behaviour is primarily caused by bounded rationality--they emphasize over and over again that their firms are simply born with decision rules (what to choose at period $t$ and how to transit to the period $t+1$ rule); these firms do not in any sense maximize. They motivate such a belief by the (undoubtedly valid) observation that profit maximization can require serious computational skill and resources. This is in contrast to our model where even non-profitmaximizing firms can (and often will) have an objective function that they maximize. We have been agnostic about what these objectives are (since we do not beljeve that there is only a single alternative to profit maximization). We do think it is important however to ask: even in a world of (rational) maximizing agents, is profit maximjzation the only behaviour that the market will select?

Second, and this is a related point, we differ in the very definition of profits. For Nelson and Winters, profits means earnings. They do not make the distinction that we emphasize between earnings and withdrawals - and as we have argued above this is an important distinction to make since the more natural definition of profits is in fact withdrawals. (Our definition is also consistent with models in financial economics that emphasize the Present Discounted Value of dividends or coupon payments as a way to price financial instruments.) Consequently, in a "fully rational" version of their model, profit maximizers must in fact be selected by the market. In contrast, it is the nature of the withdrawal process that drives our result that profit maximizers surely fail in finite time.

In some evolufionary models one can show that firms exhibiting a variety of behaviours-including profit maximizers and non-profit maximizers-can simultaneously persist in the long run. Our contribution is to provide a sharper result: in what we think is a reasonable model, after a long time practically all of the surviving firms are not maximizing profits. Blume and Easley (1992) also provide a sharp critique of rationality in evolutionary outcomes. They construct a model in which individuals make risky investments and, although nobody goes bankrupt, wealth levels fluctuate over time; the decision rule that is most likely to succeed need not be the rule consistent with utility maximization. DeLong et al. (1990) observe that rationalify is a characteristic of the environment. Hence it is perfectly possible, and this is true of their model, that behavioural rules which are non-profit maximizing are actually mutually beneficial. Hence, in their financial market model, so-called "irrational." investors can grow together and come to dominate the market. Finally, Dutta and Sundaram (1992) provide a stylized model of product market competition in which survivalist strategies come to dominate the population even as the few remaining profit maximizers come to hold most of the available wealth in the economy.

\section{APPENDIX}

\section{A.1. Proof of Theorem 3.1}

The proof will be in three steps. In the first step we will establish the existence of a $C^{2}$ function $V$ that solves the Bellman differential equation for this optimization problen. Then in the second step we shall show that this imples that $F$ is, in tact, the value function and there exists a barrier policy that is optimal. Finally, we shall. argue (a) that a firm following a batrier policy will, almost surely, fail in finite time and then use this to show (b) that, in fact, the expected failure time is finite. 
For any $C^{2}$ function $V$ let

$$
\Gamma V(y)=\frac{1}{2} s V^{\prime \prime}(p)+m V^{\prime \prime}(y)
$$

Lemma A.1. There is $b>0$ and $a C^{1}$, strictly increasing, concave (strictly concave on $[0, b]$ ) fonction $V$ satisfying

$$
\begin{aligned}
\Gamma V(y)-\gamma V(y)=0, & y \in[0, b] \\
V(0)=0, \quad V^{\prime \prime}(b)=1, & V^{\prime \prime}(b)=0, \\
V(y)=V(b)+y-b, & y \geq b .
\end{aligned}
$$

Proof. Define $\theta$ and $\lambda$ as, respectively, the positive root and the absolute value of the negative root of the quadratic function

$$
\frac{1}{2} s x^{2}+m x-r=0 .
$$

Furthermore, define the barrier $b$ from the following condition ${ }^{\text {is }}$

$$
\exp [(\lambda+\theta) b]=\left(\frac{\lambda}{\theta}\right)^{2}
$$

The function $V$ is now defined as

$$
V(y)= \begin{cases}\frac{e^{\theta y}-e^{-\lambda, \mu}}{\theta e^{\theta b}+\lambda e^{-\lambda, b}}, & y \leqq b, \\ \frac{e^{\theta b}-e^{-\lambda . t}}{\theta e^{\theta b}+\lambda e^{-\lambda b}}+(y-b) & y>b .\end{cases}
$$

On $[0, b]$, the function $V$ is proportional to $\bar{V} \equiv e^{\theta y^{\prime}}-e^{-2-\mu}$. Hence, (A.2) is equivalent to $\Gamma \vec{V}-r \vec{F}=0$, on $[a, b]$. In turn, this is equivalent to $e^{\theta y}\left(\frac{1}{2} s \theta^{2}+m \theta-r\right)-e^{-\lambda \mu}\left(\frac{1}{2} s \lambda^{2}-m \lambda-r\right)=0$. From the definition of $\theta$ and $\lambda$ (see (A.5)), this is immediate. (A.3) and (A.4) are straightforward to verify.

Since $\exp (\theta y)$ and $\exp (-\lambda y)$ are, respectively, strictly increasing and decreasing functions it follows that $V$ is a strictly increasing function. Clearly $V$ is linear beyond $b$. To see that it is strictly concave on $[0, b]$, note that $\tilde{V}^{\prime \prime}(y)=\theta^{2} e^{\theta y}-\lambda^{2} e^{-\lambda y}$. Hence $\hat{V}^{\prime \prime}(0)=\theta^{2}-\lambda^{2}<0$ and, since $\hat{V}^{\prime \prime \prime}(y)=0$ is only satisfied by $y=b, \hat{V}^{\prime \prime}(y)<0$, for all $y \in(0, b)$. So, $V$ is strictly concave over $[0, b]$. The proof of Lemma A. I is complete. II

We now prove that $V$ is, in fact, the return to the bartier policy whose barrier is defined in (A.6). Furthermore, the expected return to any other withdrawal policy is less than $V(y)$ (where $y$ is the initial capital stock).

Lemma A.2. $V$ is the walue function for the optimization problem under stzdy, furthermore, the barrier policy defined by $b$ in (A.6) is the optimal withdrawal policy. In other words,

$$
V(y)=E\left\{\int_{0}^{T} \exp (-r u) d W(u) \mid Y(0)=y, b\right\} \geqq E\left\{\int_{0}^{T} \exp (-r u) d W(u) \mid Y(0)=y, W\right\}
$$

for all withdrawal policies $W=[W(t): t \geqq 0]$.

Proof. The cumulative capital stock process $[Y(t): t \geq 0]$ generated by any withdrawal policy, as defined in (2. I) and (2.2), is a jump-Itô process (for a definition, see Harrison $(1985$, p. 63)). For any $i$, let $i=i \wedge T$. Since $V$ is a $C^{2}$ function, by Itô's lemma, applied to the function $\exp (-r) V(Y(t))$,

$$
\begin{aligned}
e^{-r i} V(Y(\hat{T}))= & V(Y(0))-\int_{0}^{i} r e^{-r u} V(Y(u)) d u+\int_{0}^{i} e^{-r u} V^{u}(Y(u)) d Y(u) \\
& +\frac{1}{2} \int_{0}^{i} e^{-r u} V^{\prime u}(Y(u)) s(Y(u)) d u+\sum_{s=1} e^{-r s} \Delta V_{s}
\end{aligned}
$$

34. Since $m>0, \lambda>\theta$. Hence (A.6) defines a positive value for the batrier $b$ 
where $\Delta V_{s} \equiv V\left(Y_{s}\right)-V\left(Y_{s-}\right)$ and is non-zero at the (countable) set of jump points of the capital stock process. Noting that $d Y(u)=m a u+s^{[/ 2} d B(u)-d W(u)$, wtiting $Y(0)=y$ and collecting terms, (A.9) yields

$$
\begin{aligned}
& e^{-x i} V(Y(t))=V(y)+\int_{0}^{\bar{t}} e^{-r \mid x}[-r V(Y(u))+\Gamma V(Y(u))] d u \\
& -\int_{0}^{i} e^{-\mu d} V^{\prime}(Y(u)) d W(u)+\int_{0}^{i} s^{[/ 2} V^{\prime}(V(u)) d B(u)+\sum_{s<i} e^{-n i t} \Delta V_{s}
\end{aligned}
$$

Upon taking expectations, the last (stochastic) integral disappears-since we are integrating with respect to a standard Brownian motion process. Furthermore, there ate no jumps in $[0, b]$. Hence, for the bartier withdrawal policy, (A.10) simplifies to

$$
\left.E e^{-x i} V(Y(\hat{f}))=V(y)-E\left\{\int_{0}^{i} e^{-r \prime \prime} V^{\prime}(Y(u)) d W(u)\right\} Y(0)=y, b\right\}
$$

In deriving (A.11) we used the fact that $-r V+\Gamma V=0$ on $[0, b]$, and that the capital stock never accurnulates past $b$, under the batrier policy. Letting $t \rightarrow \infty$ and noting that $d W(u)=0$ whenever $V^{\prime}(Y(u)) \neq 1$. the R.H.S. of (A. I I) converges to $V(y)-E\left(\int_{0}^{T} e^{-r} d W(w)(Y(0)=y, b)\right.$. The L.H.S. converges to zero. This can be seen by noting that $Y(u) \leqq$ max $(Y(0), b)$, for all $u \geqq 0$. We conclude

$$
V(y)=E\left\{\int_{0}^{T} e^{-r+t} d W(u) \mid Y(0)=y_{3} b\right\}
$$

Finally note that for any other withdtawal policy, (A.10) and (A.11) can be tewritten as

$$
\begin{aligned}
& E e^{-r i} Y\left(Y(\hat{D}) \leq V(y)-E\left\{\int_{0}^{\hat{t}} e^{-j \cdot d} d W(u) \mid Y(0)=y, W\right\}-E \Sigma_{s, j} e^{-r s} \Delta Y_{s}\right. \\
& \left.+E\left\{\int_{0}^{s} e^{-x^{\prime \prime}}\left(1-V^{\prime}(Y(a))\right) d W(u)\right\} Y(0)=y, W\right\} \\
& +E \sum_{s=t} e^{-\mathrm{s} s}\left(1-V^{\prime}(Z(s))\right)(Y(s-)-Y(s))
\end{aligned}
$$

where, $Z(s) \in(Y(s), Y(s-))$ such that $V(Y(s-))-V(Y(s))=V^{\prime}(Z(s))[Y(s-)-Y(s)]$.

The inequality follows from the fact that $\Gamma V(y)-r V(y)<0$ on $(b, \infty)$. Given the properties of $V^{\prime}$, the last two terms in (A.12) are non-positive as well. Finally, we know that $E e^{-r t} V(Y(D))>0$. Sa we have

$$
V(y) \geq E\left\{\int_{0}^{T} e^{-t \omega d} d W(u) \mid Y(0)=y, W\right\}+E \sum_{s=T} e^{-r s} \Delta Y_{s} .
$$

The proof of Lemma A.2 is complete. II

Now we formalize the intuition which suggest that a firm following a barriet withdrawal policy will a.s. fail in finite time, regardless of the initial capital stock. It is clear that $P(T<\infty \mid Y(0)=y)=P(T<\infty) Y(0)=b)$, for $y>b$. Hence, it suffices to show:

Lemma A.3a. For $y \in[0, b], P(T<\infty \mid Y(0)=y)=1$.

Proof. Consider the following withdrawal policy: $d W(Y(c)=0$, for $y \in[0, b]$, as in a barrier policy and $d W(Y(f))=w>m$, for $\mu>b$. Let $\dot{P}$ denote the probability of survival under this policy; evidently, $\hat{P}(T<\infty \mid Y(0)=y) \leqq P(T<\infty \mid Y(0)=y)$. We will show that $\bar{P}(T<\infty \mid Y(0)=y)=1$.

Let $N(y) \equiv$ inf $\{r: Y(t)=2 b \mid Y(0)=y\}$, for $y \in[0, b]$. Note that if a sample path reaches zero before it hits $2 b$, then $N(y) \equiv \infty$. Furthermore, by the Strong Markov Property,

$$
\tilde{P}(Y(t)>0, t \geq N(y)[Y(N(y))=2 b)=P(Y(t)>0, t \geq 0 \mid Y(0)=2 b)
$$

Hence,

$$
\hat{P}(T=\infty \mid Y(0)=b)=\tilde{P}(N(b)<\infty) \cdot \tilde{P}(T=\infty \mid Y(0)=2 b)=\ddot{P}(N(b)<\infty) \cdot \tilde{P}(T=\infty \mid Y(0)=b)
$$

Since the capital stock is a process with a negative drift over $(b, \infty)$ if follows that the process a.s. drifts 
down to $b$ in finite time after starting at $2 b$; that explains $(A, 13)$. Since $\tilde{P}(N(b)<\infty)<1,($ A.13) can hold only if $\tilde{P}(T=\infty \mid Y(0)=b)=0$. Clearly, for any $y \in(0, b), \tilde{P}(T=\infty \mid Y(0)=y) \leqq \tilde{P}(T=\infty \mid Y(0)=b)$. $\|$

Lemma A.3a will now be used to show that the expected time to failure is finite; indeed, we will explictuly compute the expected time:

Lemma A.3b. The expected time to failure, for a barrier policy b with fixed drift-variance (m, s), is given $b y:$

$$
E(T \mid Y(0)=y)= \begin{cases}\left.a\left(1-e^{-2 m}\right)\right\}-\frac{y}{s}, & y \in[0, b] \\ E(T(Y(0)=b), & y>b .\end{cases}
$$

where, $a=s / 2 m^{2} \exp ((2 m / s) b)$.

Proof. For ease of exposition let us call the function in (A.14), $H(y)$. It is easy to show that this function is $C^{2}$ and satisfies the following three properties:

$$
\begin{gathered}
\Gamma H(y)+1=0, \quad y \in[0, b] . \\
H(0)=0, \\
H(y)=H(b), \quad y \geqslant b \\
\Leftrightarrow H^{\prime}(y)=0, \quad y \geqq b .
\end{gathered}
$$
policy,

By mimicking the arguments in Lemma 4.2 it then follows that, for the Itô process generated by the barrier

$$
E H(Y(\ell))=H(y)+E \int_{0}^{i} \Gamma H(Y(u)) d u-E \int_{0}^{i} H^{\prime}(Y(u)) d W(u)
$$

Since $T<\infty$ a.s., as $t \rightarrow \infty, Y(\hat{l})=0$ a.s.; hence, from (A.15) it foltows that $E H(Y(i)) \rightarrow 0$, as $t \rightarrow \infty$. A bartier policy is a.s. restricted to the domain $[0, b]$; hence, using $(A, 15), E \int_{0}^{i} \Gamma H(Y(u)) d a$ converges to $-E T$. Finally, $H^{\prime}(Y(u)) d W(u)=0$ for a barrier policy. Collecting all this together we have

$$
0=H(y)-E T \text {. }
$$

The proof of the lemma and hence of Theorem 3.1 is complete. It

\section{A.2. Proof of Theorem 3.2: The main theorem}

In this subsection we will prove Theorem 3.2. We will do this th three steps. First we will show that the value functions for the bounded withdrawal problem, as well as their first two derivatives, converge to the value function, and the first two derivatives, of the unbounded withdrawal problem. ${ }^{35}$ Second, we will show that, consequently, the unbounded value function satisfies the Bellman equation for this problem. Finally we will characterize the optimal withdrawal and mean-variance policies.

An important point to note is that when the mean and variance controls change (possibly nonlinearly) with the level of capital stock, it is no longer possible to explicitly construct the value function, as we did for Theorem 3.1. We follow instead an analytical route. Write $V_{n}$ tor the walue function for the bounded withdrawal problem with upper bound $\bar{w}_{n}$

Lemma A.4. If $V_{n}$ and $V$ are $C^{2}$ functions, then, on a subsequence, $V_{n} \rightarrow V$ and $V_{n}^{\prime} \rightarrow V^{\prime}$ pointwise. Also $V_{n}^{u t} \rightarrow V^{\prime \prime}$ on the set $\left\{y: V^{\prime}>1\right\}$.

Proof. By definition, $\left(V_{\mathrm{h}}(y): n \geq l\right\}$ is an increasing sequence, for ewery $y$. Furthermore, the sequence is bounded above by $V(y)$. Hence the sequence has a limit; call the lirnit function $L(\cdot)$.

Evidently, $L \leqq V$. In fact, it must be the case that $L=F$, since it can be shown that any feasible withdrawal policy in the unbounded withdrawal problem can be approximated arbitarily closely by withdrawal policies that have large bounded withdrawal rates.

35. Here, and everywhere else in this paper, by the unbounded withdrawal problem we mean the (original) problem in which jump withdrawals ate possible. By the bounded withdrawal problen, with bound w, we mean the problem in which the rate of increase in $W(\cdot)$ is bounded above by $\bar{w}$. 

$[0, \bar{y}]$.

We now prove that the first two derivatives, $V_{\mu \prime}^{\prime}$ and $V_{1 \prime}^{\prime \prime}$ are uniformly bounded on every compact interval

Lemma A.5. There is a bound $M$, such that $\left|V_{\mu \prime}^{\prime}(y)\right|<M$ for all $n$ and $y \in[0, \bar{y}]$.

Proof. Fix a level of capital stock $y$ and a bound on withdrawal, $w_{n}$. Consider the following optimization probiem, $\left(F_{n}\right)$, for any initial state $y+\varepsilon, \varepsilon>0$;

$\left(P_{n}\right)$ Withdrawals are non-negative and unbounded. The first time the state hits $y$, it is absorbed with terminal payoff $V_{n}(\gamma)$.

Incidentally, as everywhere else, the technology correspondence for problem $(P, \ldots)$ continues to be $A(\cdot)$ and the objective function continues to be the present discounted value of withdrawals. Denote by $S_{n}(\cdot)$ the value function for problem $\left(P_{n}\right), n \geq 1$.

It should be clear that $S_{\mu} \geq V_{\mu}$. Since $S_{\mu}(y)=V_{\mu}(y)$, it further follows that

$$
V_{\mathrm{n}}(y+\varepsilon)-V_{\mathrm{n}}(y) \leqq S_{\mathrm{n}}(y+\varepsilon)-S_{\mathrm{n}}(y), \quad \varepsilon>0 .
$$

We now show that the following monotonicity property holds:

$$
S_{n+1}(y+\varepsilon)-S_{n+1}(y) \leqq S_{n}(y+\varepsilon)-S_{n}(y), \quad \varepsilon>0, \quad n \geqq 1 .
$$

To establish inequality (A.20), consider the policy that solves problem $\left(P_{n+1}\right)$. Denote this policy $\left(\theta_{n+1}\right){ }^{36}$ It follows that

$$
S_{n+1}(y+\varepsilon)=E\left[\int_{0}^{\bar{T}} e^{-r s} d W(s) \mid \theta_{n+1}\right]+E e^{-r t} S_{n+1}(y) .
$$

To avoid writing long expressions let us denote the first term in $(A .21), B(n+1)$, i.e. $B(n+1) \equiv$ $E\left[\int_{0}^{+} e^{-r+1} d W(s)\left[\theta_{\mu+1}\right]\right.$. Of course, $\hat{T}$ is the time of absorption at $y$ under the policy $\theta_{\mu+1}$, ie.

$$
T=\inf \left\{r \mid Y(t)=y: Y(0)=y+\varepsilon_{1} \theta_{n+1}\right\}
$$

A teasible policy for the problem $\left(P_{n}\right)$ is $\theta_{n+1}$. Hence,

$$
\begin{aligned}
S_{\mu}(y+\varepsilon) & \geq B(n+1)+E e^{-r \vec{\gamma}} S_{n}(y) \\
& \Rightarrow \\
S_{n}(y+\varepsilon)-S_{n}(y) & \geqq B(n+1)-\left(1-E e^{-r t}\right) S_{n}(y) \\
& \geq B(n+1)-\left(1-E e^{-r t}\right) S_{n+1}(y) \\
& =S_{n+1}(y+\varepsilon)-S_{u+1}(y) .
\end{aligned}
$$

In deriving (A.22) we used the fact that $S_{n,}(y)=V_{m}(y) \leqq V_{n+1}(y)=S_{n+1}(y)$. The inequality (A.20) has been proved. Consequently, using (A.19),

$$
V_{1}(y+\varepsilon)-V_{n}(y) \leqq S_{1}(y+\varepsilon)-S_{1}(y)
$$

By similat reasoning it follows that

$$
S_{1}(y+\varepsilon)-S_{l}(y)=B(1)-\left(1-E e^{-5} \cdot\right) S_{1}(y)
$$

Note that the optimal policy for problem $\left(p_{1}\right)$ is a feasible poticy for the original unbounded rate optimization problem, i.e.

$$
V(y+E) \geqq B(1)+E e^{-r+\frac{1}{V}} V(y) .
$$

From (A.25) and (A.26) it follows that

$$
S_{1}(y+\varepsilon)-S_{1}(y) \leqq[V(y+\varepsilon)-V(y)]+\left[1-E e^{-r \dot{T}}\right]\left[V(y)-S_{1}(y)\right] .
$$

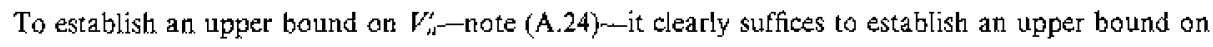

$$
\lim _{e \rightarrow 0} \frac{l-E e^{-r} t}{\varepsilon}
$$
policies.

36. If problem $\left(P_{n+1}\right)$ has no solution the arguments that follow can be reproduced using $\varepsilon$-optimal 
This is not difficult to do since $1-E e^{-s \tilde{t}}$ is bounded by the solution to the pure survival problem:

$$
Z(\varepsilon)=\operatorname{Max} 1-E e^{-r f \varepsilon} \text { where } T(\varepsilon) \equiv \inf \{t: Y(t)=y \mid Y(0)=y+\varepsilon\} \text {. }
$$

Note that $Z(0)=0$. It is known that

$$
\lim _{\varepsilon \rightarrow 0} \frac{Z(\varepsilon)}{\varepsilon}
$$

is finite. We have therefore proved Lemma A.5, i.e. we have shown that $V_{n}^{\prime}$ is uniform]y bounded on [0, $\left.\bar{y}\right]$. This follows from our demonstration of the upper bound because, additionally, $V_{n}^{\prime} \supseteq 0$. II

Lemma A.6. $V_{n}^{\prime \prime}$ is uniformly bounded, i.e. there is $M<\infty$ s.t. $\left\{V_{n}^{\prime \prime}(y) \mid<M\right.$, for all $n$ and $y \in[0, \bar{y}]$.

Proof. Since $V_{n}$ is $C^{2}$, an apptication of Ito's lemima shows that it satisfies the Bellman equation for the (bounded withdrawal) problem

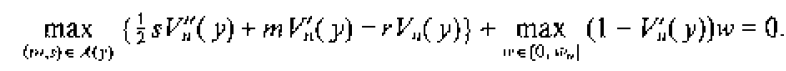

If $V_{n}^{\prime} \geq 1$, then (A.28) can be rewtitten as

$$
\max _{|+| s \mid}\left\{\frac{2 m}{s} V_{\mathrm{n}}(y)-\frac{2 r}{s} V_{\mathrm{n}}(y)\right\}=-V_{n}^{* t}(y)
$$

Evidently (A.29) implies a bound, independent of $n$ and $y$, for $V_{n}^{u t}$ since just such a uniform bound has been established already for $V_{\mu}$ and $V_{n}^{\prime}$.

If $V_{r 1}^{x}<1$, it is useful to distinguish between two cases. that

Case 1. $V_{n}^{\prime \prime} \geqq 0$. In this case, an upper bound for $V_{t_{2}}^{n}$ follows because the Bellman equation (A.28) implies

$$
\frac{1}{\mathfrak{s}} \tilde{s}(y) V_{m}^{\prime \prime}(y)+\left[\tilde{m}(y) V_{n}^{\prime}(y)+\bar{w}_{n}\left(1-V_{m}^{\prime}(y)\right)\right] \leq r V_{M}(y),
$$

where, recall, $m(y)$ is the largest feasible mean in the feasible set $A(y)$. Since $m(y)>0$, by hypothesis, the term in brackets is positive. Evidently (A.30) implies a bound on. $V_{n}^{\prime \prime}(y)$, independent of $n$ and $p$.

Case 2. $V_{p}^{u}<0$. Consider the returns to the following: start at $y+\varepsilon$ and employ the fixed mean-variance policy $(m, S)$ and withdraw at rate $\bar{w}_{n}$ throughout. The first time the state hits $y$, the process is absorbed with terminal payofss $V_{n}(y)$. Denote the lifetime teturns to this policy, $K_{n}(y+\varepsilon)$. Two things are known about this function. Fitst it satisfes the following differential equation

$$
\frac{1}{2} s K_{n}^{\prime \prime}\left(y_{\varepsilon}\right)+\left(m-\bar{w}_{n}\right) K_{n}(p+\varepsilon)-F K_{n}\left(y_{\varepsilon}\right)+\bar{w}_{t}=0, \quad \varepsilon \geq 0
$$

Second the solution to the differential equation, with boundary condition $K_{N}(y)=V_{3}(y)$, is

$$
K_{n}(y+\varepsilon)=\frac{\bar{w}_{n}}{\rho}\left(1-e_{n}^{-\lambda_{s}}\right)+\dot{e}^{-\hat{\lambda}_{n} \varepsilon} V_{n}(y)
$$

where $\hat{\lambda}_{m}$ is given by

$$
\hat{\lambda}_{n}=\frac{1}{s}\left[\left(h-\omega_{\mu}\right)+\sqrt{\left(\hat{m}-\bar{w}_{n}\right)^{2}+2 r \hat{s}}\right] .
$$

It is straightforward to see that $V_{M}(y+\varepsilon) \geq K_{M}(y+\varepsilon)$, for all $\varepsilon>0$ and-since $V_{\mathrm{N}}(y)=K_{\mathrm{H}}(y)$-that $V_{\mathrm{s}}(y) \geq K_{\mathrm{s}}(y)$. From (A.31) and the Bellman equation it then follows that

$$
\begin{aligned}
& \max _{(\mu n, s] \equiv A(\mu)}\left\{\frac{1}{2} s V_{n}^{\prime \prime}(y)+m V_{H}^{\prime}(y)\right\} \geqq \frac{1}{2} s K_{n}^{\prime \prime}(y)+\hat{m} K_{n}^{\prime}(y) \\
& =K_{n}^{\prime}(y)\left[\mu-\frac{1}{2} s \hat{\lambda_{N}}\right] \\
& =\hat{A}_{n}\left[\frac{\bar{w}_{n}}{r}-V_{n}(y)\right]\left[\hat{m}-\frac{1}{2} \hat{\jmath} \hat{\lambda}_{n}\right]
\end{aligned}
$$


Using L'Hôptral's rule it is possible to show that $\hat{\lambda}_{n}\left[\bar{w}_{H} / r-V_{n}(y)\right] \rightarrow 1$, as $\bar{w}_{n} \rightarrow \infty{ }^{37}$ The root $\hat{\lambda} \rightarrow 0$ and

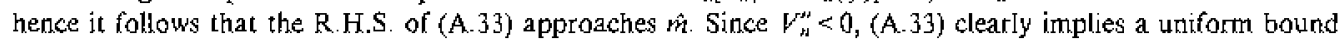
for $V_{n}^{\prime \prime}$. The proof of Lernma A.6 is complete. II

We now return to the proof of Lemma A.4. Since by the fundamental theorem of calculus,

$$
V_{n}^{\prime}(z)-V_{t}^{\prime}(y)=\int_{1}^{x} V_{n}^{\prime \prime}(x) d x,
$$

the uniform bound on $V_{n}^{\prime \prime}$ implies, from (A.34), that $V_{n}^{\prime}$ is an equicontinuous family. Hence, possibly on a subsequence, $V_{n}^{\prime}(y)$ has a limit for every $y \in[0, y]$. Call this limit $l(y)$.

Another invocation of the fundamental theorem says

$$
V_{n}(z)-V_{n}(y)=\int_{z}^{y} V_{n}^{\prime}(x) d x
$$

Taking limits in (A.35), and applying the Dominated Convergence Theorem, we have

$$
V(z)-V(y)=\int_{s}^{\mu} f(x) d x .
$$

In turn (A,36) says that $l=V^{\prime}$, i.e. that $V_{n}^{\prime} \rightarrow V^{\prime}$, on $[0, \bar{j}]$. Finally, on $\left\{y: V^{\prime}>1\right\} \cap[0, \bar{y}]$, we know that for large $n, V_{n}^{\prime} \geq 1$. Hence,

$$
-V_{n}^{\prime \prime}(y)=\max _{(j+s)=A(y)}\left\{\frac{2 m}{s} V_{n}^{\prime \prime}(y)-\frac{2 r}{s} V_{n}(y)\right\} .
$$

Since $V_{n} \rightarrow V$ and $V_{n}^{\prime} \rightarrow V^{\prime}$, by the maximum theorem (Berge (1963)) the R.H.S. of (A.37) converges to a limit; call the limit $-L(y)$. We therefore have

$$
-L(y)=\max _{\{, y, s] \in A(y)}\left\{\frac{2 m}{s} V^{\prime}(y)-\frac{2 r}{s} V(y)\right\} .
$$

Since $L=\lim V_{t i 1}^{\prime \prime}$ a further use of the fundamental theorem, via (A 34) yields $L=V^{u t}$. The proof of the lemma is complete. if

Lemma A.7. On the set $\left\{y: V^{\prime}>1\right\}$, as well as its limit points, the Betlman equation

$$
\max _{(m, s) \in A(y)}\left\{\frac{1}{2} s V^{\prime \prime}(y)+m V^{\prime \prime}(y)-r V(y)\right\}=0,
$$

is satisfied.

Proof. We have atready shown that (A.39) is satisfed on $\left\{y: V^{\prime}(y)>1\right\} \cap[0, \hat{y}]$ since that equation is precisely (A.38). Actually, the equation halds on the entire set $\left\{y: V^{\prime \prime}>1\right\}$ since $\bar{y}$ was atbitrarily chosen. Finally, if $z$ is a limit point of $\left\{y: V^{\prime}(y)>1\right\}$, evidently the fact that $V$ is $C^{2}$-and the maximum theotem-shous that the Bellman equation holds at $z$ as well. The lemma is proved. II policies.

We are, at last, ready to characterize the value function and the optimal (withdrawal and mean-variance)

Lemma A.s. (Value Function). There is a finite barrier $b^{*}$ such that the value function $V$ is strictly concave with slope greater than 1 on $\left[0, b^{*}\right)$ and linear with unit slope on $\left[b^{*}, \infty\right]$.

Proof. Since $V(y+\epsilon) \geq \epsilon+V(y)$, it immediately follows that $V^{\prime \prime}(y) \geqq 1$, for all $y$. Furthermore, $V^{\prime}(y)=$ 1 implies that $V^{\prime \prime \prime}(y)=0$. So if such a $\hat{y}$ is a limit point of the set $\left(V^{\prime}>1\right\}$ it follows from the Belinan equation, (A. 39), that

$$
V(\hat{y})=\frac{m(\hat{j})}{r}
$$

where, recall, $\dot{m}(\hat{y})$ is the maximum drift in $A(\hat{y})$. From the decreasing returns assumptions, (A. 3$)$, it futher

37. This is understandable; after all it says that $K_{n}^{\prime}(\mu) \rightarrow 1$, as $\bar{w}_{n} \rightarrow \infty$. This is what one should expect because $K_{n}$ corresponds to the returns from withdrawing at the maximal rate. Hence, $K_{n}(y+\varepsilon)-K_{m}(y)$ should approach $\varepsilon$. 
follows that there can be at most one such point. This is because $y_{t} \neq p_{2}$ and $V\left(y_{i}\right)=\vec{m}\left(y_{j}\right) / r, t=1,2$ yields a contradiction: it implies $y_{1}-y_{2} \leqq V\left(y_{1}\right)-V\left(y_{2}\right)=\hat{m}\left(y_{1}\right) / r-m\left(y_{2}\right) / r$.

The set $\left\{y: V^{\prime}(y)>1\right\}$ is open and therefore, is the untion of disjoint open intervals. If there are two such intervals $\left(a_{1}, b_{1}\right)$ and $\left(a_{2}, b_{2}\right)$, we have a contradiction. To see this, suppose, without loss of generality, that $b_{1} \leq a_{2}$

Claim I. $a_{1}=0$ : Else, $V\left(a_{1}\right)=m\left(a_{1}\right) / r$ and $V\left(b_{1}\right)=m\left(b_{1}\right) / r$ and we have a contradiction.

Claim 2. $b_{2}<\infty_{\text {; }}$ this implies that there are no withdrawals if the state crosses $a_{2}$. After all, $V(y)>\varepsilon+V(y-\varepsilon)$ for $\varepsilon>0$. But that contradicts the monotonicity of $V$ because, with no withdrawals, $V(y)=$ $E e^{-\tau} V(y-\varepsilon)$, where $T$ is the fitst time the state hits $y-\varepsilon$, startitig from $y$.

With the two intervals we now hawe a contradiction since $V\left(b_{1}\right)=m\left(b_{1}\right) / r, V\left(b_{2}\right)=m\left(b_{2}\right) / r$ and $b_{1}<b_{2}$. Collecting all this we conclude: there is $b^{*}<\infty$ s.t. $V^{\prime}>1$ an $\left(0, b^{*}\right)$ and $V^{*}=1$ on $\left[b^{*}, \infty\right)$

In order to show that $V$ is, in fact, strictly concave on $\left(0, b^{*}\right)$, we will first show that $V^{\prime \prime}$ has the same signt on the entire interval. If not, there will be $a \in\left(0, b^{*}\right)$ such that $V^{\prime \prime}(a)=0$. From the Bellnan equation it then follows that

$$
V(a)=\frac{m(a)}{r} V^{\prime}(a)>\frac{m(a)}{r}
$$

Since $V\left(b^{*}\right)=m\left(b^{*}\right) / r$, it futher follows that

$$
\frac{\bar{m}\left(b^{*}\right)}{r}-\frac{\bar{m}(a)}{r}>V\left(b^{*}\right)-V(a)>b^{*}-a
$$

Evidently (A.41) yields a contradiction. Finally note that it cannot be the case that $V^{*}>0$ on $\left(0, b^{*}\right)$. That would be inconsistent with the tact that $V^{\prime}\left(b^{*}\right)=1$. The lemmia is proved. II

Lemma A.9. (Optimal Withdtawal and Mean-Variance Policy). The barrier policy characterized by barrier $b$ s.t. $V^{\prime}(b)=\mathrm{I}$ and $(M(y), S(y))=\arg \max \left(\frac{1}{2} s V^{\prime \prime}(y)+m V^{\prime \prime}(y)\right\}$, th the optimal policy.

Proof. Applying Ito's lemma to the function $e^{-s i} V(Y(\hat{A}))$ and the Ito process generated by the barter policy on $\left(0, b^{*}\right)$, we have

$$
\begin{aligned}
e^{-r i} V(Y(O))= & V(y)+\int_{0}^{i} e^{-+\nu}\left[-r V(Y(u))+\frac{1}{2 r} S(Y(u)) V^{\prime \prime}(Y(u))\right. \\
& \left.+M(Y(u)) V^{\prime \prime}(Y(u))\right] d u-\int_{0}^{i} e^{-r x} V^{\prime}(Y(u)) d W(u)+\int_{0}^{i} s^{1 / 2}(Y(u)) V^{\prime}(Y(u)) d B(u)
\end{aligned}
$$

From the defintion of $M(\cdot), S(\cdot)$, the Bellman equation (A.31) and the fact that the process stays in $[0,6]$ a.s., it follows that the expected value of the second term in $(A .42)$ is zero. So we have

$$
E e^{-1 \cdot i} V(Y(b))=V(y)-E \int_{0}^{j} e^{-r u} V^{x}(Y(u)) d W(u)
$$

Letting $t \rightarrow \infty$, noting that $E e^{-\cdot i} V(Y(t)) \rightarrow 0$ and $V^{\prime}(Y(u)) \neq 1$ implies that $d W(u)=0$, by arguments identical to that in Lemma A.1, we get the fact that $V(y)=E\left(\int_{0}^{T} e^{-r s} d W(u) \mid Y(O)=y,(M, S), b\right\}$.

Now note that $\operatorname{Max}_{(m, s)=A}\left\{\frac{1}{2} a V^{\prime \prime}(y)+m V^{\prime}(y)-r V(y)\right\} \leq 0$, fot $y \geq b$. This follows from the fact that $V^{\prime \prime}(y)=V^{\prime \prime}(b)=0, V^{\prime}(b)=1$ while $V(y)>V(b)$ and the maximum is zero at $y=b$. Using this it follows that for an arbitrary policy, (A.38) implies

$$
E e^{-r \bar{j}} V\left(Y(D) \leq V(y)-E \int_{0}^{i} e^{-r w} d W(u)-E \sum_{s=i} e^{-r r} \Delta Y_{s} .\right.
$$

Letting $t \rightarrow \infty$, and noting that $E e^{-r i} V(Y(t)) \rightarrow 0$, we conclude that

$$
V(y) \geqq E \int_{0}^{T} e^{-r y s} d W(u)+E \sum_{s=r} e^{-r s} \Delta Y_{s}
$$

for such a policy. The lemma is proved. II 
So far we have only used assumptions (Tl)-(T3). We will now use (T4) and (T5) to prove:

Lemma A.10. (Further Characterization of the Optimal Mean-Variance Policy). The optimat mean and variance increase with the size of capital stoch $y$ (in $\left[0, b^{*}\right]$ ).

Proof. On $[0, b]$, the optimal mean-variance controls are selections from the maximizers of the Bellman equation (A.39). Since $V^{\prime}>0$ it follows that we can restrict attention to the patr $(g(s, y), s)$, i.e. we can restrict attention to the maximum mean associated with every variance control. Furthermore, since $g(, j)$, is strictly concave, there is a unique maximizer; $S(y)$ with associated mean $g(S(y), y)$. By the maximum theorem, $S(-)$ is a continuous function.

By (T4), the set of feasible variances, $B(y)$, is an interwal that increases with $y$ in the set-inclusion sense. Denote $\bar{b}(y)$ to be the maximum feasible variance, i.e.

$$
\bar{b}(y) \equiv \max \{s \mid(m, s) \in A(y)\} .
$$

By hypothesis $S(0)$ is an interior choice, i.e. $S(0) \in$ int $B(0)$. Hence, by the continuity of the function $S(-)$, $S(y)$ is also an interior choice for some neighbourhood of $y=0$. Fix $y$, in this neighbourhood. The first-order condition of the Bellman maximization yields

$$
\frac{1}{2} V^{\prime \prime}\left(y_{1}\right)+g_{1}\left(S\left(y_{1}\right), y_{1}\right) V^{\prime \prime}\left(y_{1}\right)=0 .
$$

Substituting back into the Bellman equation and collecting terms yields

$$
g-s g_{1}=r \frac{V}{\boldsymbol{Y}^{r}}
$$

where the arguments of (A.46) ate $y_{1}$ and $S\left(\mu_{1}\right)$. (A.46) implies that there is a neighbourhood of $y_{1}$ in which the optimal choice continues to be interior and $S(\cdot)$ is an increasing function. The first part of the assertion is obvious. The second part follows because, by (T5),

$$
g\left(S\left(y_{2}\right), y_{2}\right)-S\left(y_{2}\right) g g_{1}\left(S\left(y_{2}\right), y_{2}\right) \leqq g\left(S\left(y_{1}\right), y_{2}\right)-S\left(y_{1}\right) g\left(S\left(y_{1}\right), y_{2}\right) \leqq g\left(S\left(y_{1}\right), y_{1}\right)-S\left(y_{1}\right) g\left(, S\left(y_{1}\right), y_{1}\right)
$$

whenever we have $y_{2}>y_{1}$, but $\left.S\left(y_{2}\right)\right)<S\left(y_{1}\right)$. The inequalities yield a contradiction because the very first expression is equal to $r\left(V\left(y_{2}\right) / V^{\prime}\left(y_{2}\right)\right)$ and the last equals $\left.m\left(y_{1}\right) / V^{\prime}\left(y_{1}\right)\right)$.

A symmetric argument applies if $y_{2}<y_{1}$ but $S\left(y_{2}\right)>S\left(y_{1}\right)$. Hence, we have shown that $S(1)$ is increasing on a neighbourhood of $y_{l}$. In this fashion we can add contiguous neighbourhoods $\left(y_{k}, y_{k+1}\right)$ and we may be able to do this all the way to $y=b^{*}$. If we canthot, then there will be a limit point $y^{\prime \prime}=\lim _{k \rightarrow \alpha} y_{k}$ such that the optimal choice at $y^{\prime}$ is $\bar{b}\left(y^{\prime}\right)$.

We now claim that for $y>y^{\prime}$, the optimal choice must continue to be $\bar{b}(y)$. If not then it will be an interiot choice for some $y$ and $S(\cdot)$ will have to decrease on an interval. But we have shown that to be impossible.

To summarize, we have shown that between $y_{1}$ and $b^{*}, S(\cdot)$-and hence $M(\cdot)$-is an increasing function. Since $y_{1}$ can be chosen arbitrarily close to 0 , we have actually shown that $S\left(\right.$ ( ) increases between 0 and $b^{*}$.

The proof of the lemma-and Theorem 3.2-is complete. II

\section{A.3. Proof of Corollary 3.5}

Consider an optimal mean-variance policy $\left[M(y), S(\mu) ; y \in\left(0, b^{*}\right)\right]$; denote its expected time to failure from initial stock $f$ to be $E T^{*}(j)$. By assumption (TS), for all capital stocks, $M(y), S(y) \in A\left(b^{*}\right)$, the available technology at the highest capital stock $b^{*}$. In turn this implies that the expected time to failure under this policy is bounded above by the maximum expected time to failure, $H(\bar{y})$, among all bartier policies drawn from the constant technology $A\left(b^{*}\right)$, i.e.

$$
E T^{*}(\bar{y}) \leqq H(\bar{y}) \equiv E T\left(\bar{y} ; m(y), s(p) \in A\left(b^{*}\right), y \in\left(0, b^{*}\right)\right)
$$

(and instantaneous withdrawal down to $b^{*}$ whenever $y$ increases beyond that level). By arguments similar to those of Lenma A. 3 b we will now show that

$$
H(y)=\alpha\left(1-e^{-\alpha r^{\prime} s_{k r}}\right)-\frac{y}{m}, y \in\left(0, b^{*}\right)=H\left(b^{*}\right), \quad y \geq b^{*}
$$

where $\dot{m} / \hat{s}=\arg \max m / s:(m, s) \in A\left(b^{*}\right)$. Note that $H$ satisfies the Bellman equation

$$
\max _{\left\{(\mu, s) \in A\left(b^{*}\right)\right.}\left\{\frac{1}{2} s H^{\prime \prime}(y)+m H(y)\right\}-1=0, \quad y \in\left(0, b^{*}\right)
$$


By arguments identical to those in Lemma A 3 b it follows that $H(y)$ is in fact the expected time to failure under the constant mean-variance policy $(m, s)$ (with bartier at $b^{*}$ ). Furthernore, by arguments identical to the proofs of Lemma A.2 or A.9, it follows that $H(y) \geqq E T(y)$, for all other feasible policies.

Acknowledgements. The research was begun while P. K. Dutta was at The University of Wisconsin, Madison and R. Radner was at the Mathematical Sciences Reseatch. Center, AT\&T Bell Laboratories. The first author would like to acknowledge help from NSF Grant \#SBR-9410485 during the period of tesearch on this paper. This version of the paper has benefitted from the comments of an editor and two anonymols referees. We would also like to acknowledge helpful comments from seminar participants at wisconsin, Pennsylvania, Northwestern, Carnegie-Mellon, Bellcore, Stanford, Harvard-MIT, and Princeton.

\section{REFERENCES}

ALCHIAN, A. (1950), "Uncertainty, Evolution and Economic Theory", Joumal of Political Economy, 21, 3953.

BERGE, C. (1963) Topological Spaces (New York: Macrnihlan Press)

BLUME, L. and EASLEY, D. (1992), "Evolution and Market Behavior", Jounal of Economic Theory, 58,940.

DELONG, J. B., SCHLEIFER, A., SUMMERS, L. and WALDMAN, M. (1990), "Noise Trader Risk in Financial Markets", Joumal of Political Economy, 98, 703-738.

DUTTA, P. K. (I994), "Bankruptcy and Expected Utility Maximization", Journol of Economic Djnomics and Contwol, 18, 539-560

DUTTA, P. K. and RADNER, R. (1994a), "Optimal PrincipaI-Agent Contracts for a Class of Incentive Schemes: A Characterization and the Rate of Approach to Efficiency", Economic Theory, 2, 483-504

DUTTA, P. K, and RADNER, R. (1994b), "Moral Hazard", in R. Aumatiti and S. Hart (eds.), Handbook of Game Theory, Vol. 2 (Amsterdam: North-Holland).

DUTTA, P. K and RADNER, R. (1998), "Profit Maximization and the Market Selection Hypothesis", (Working Paper, Columbia University).

DUTTA, P. K. and SUNDARAM, R. (1992), "Survival and the Art of Profit Maximization" (Mimeo, University of Rochester)

FRIEDMAN, M. (1953) Essays in Positive Economics (Chicago: University of Chicago Ptess).

HARRISON, J. M. (1985) Brownian Motion and Stochastic Flow Systems (New York: Wiley).

KARATZAS, I. and SHREVE, S. (1988) Brownian Motion and Stochastic Calculus (New York: SpringerVerlag).

KRYLOV, N. (1980) Controlled Diffusion Processes (New York: Springer-Verlag).

MERTON, R. C. (1990) Conthwous Time Finance (Oxford: Basil Blackwell)

NELSON, R. and WINTER, S. G. (1982) An Evolutionary Theory of Economic Change (Cambridge: Bellknap Press).

PATEL, J., ZECKHAUSER, R. and HENDRICKS, D. (1991), "The Rationality Struggle: IIIustrations from Financial Markets", American Economic Review, 2, 232-236.

PESTEIN, V. and SUDDERTH, W. (1988), "Continuous-Time Casimo Problems", Mathematics of Operations Research, 13, 364-376.

RADNER, R. (1985), "Repeated. Principal-Agent Games with Discounting", Econtometrica, 53, $1173-1198$.

RADNER, R, (1998), "Profit Maximization with Bankruptcy and Variable Scale", Joumal of Economic Dynamics and Control, 22, 849-867.

RADNER, R. and SHEPP, L. A. (1996), "Risk ws. Profit Potentiat: A Model for Corporate Strategy", Joumal of Economic Dpmamics and Control, 20,1373-1393.

SHUBIK, M. and THOMPSON, G. L. (1959), "Games of Economic Survival", Naval Research Logistics Quarterly, 6, $111-123$.

WHITT, W. (1991), "A Review of $L=\lambda W$ and Extensions", Queueing Systems, 2, $235-268$.

WINTER, S. G. (1987), "Competition atnd Selection", in J. Eatwell, J. Milgate and P. Newrin (eds.), The New Palgrave (New York: Stockton Press), 545-548. 